\title{
CD38 is involved in cell energy metabolism via activating the PI3K/AKT/mTOR signaling pathway in cervical cancer cells
}

\author{
SHAN LIAO ${ }^{1,2^{*}}$, LIN LIANG $^{2 *}$, CHUNXUE YUE $^{2}$, JUNYU HE $^{2}$, ZHENGXI HE $^{2}$, \\ XI JIN ${ }^{2}$, GENGQIU LUO ${ }^{3}$ and YANHONG ZHOU ${ }^{1,2}$ \\ ${ }^{1}$ Department of Oncology, Xiangya Hospital, Central South University, Changsha, Hunan 410008; ${ }^{2}$ Cancer Research Institute, \\ Basic School of Medicine, Central South University, Changsha, Hunan 410078; ${ }^{3}$ Department of Pathology, \\ Xiangya Hospital, Basic School of Medicine, Central South University, Changsha, Hunan 410008, P.R. China
}

Received August 9, 2019; Accepted February 14, 2020

DOI: $10.3892 /$ ijo.2020.5040

\begin{abstract}
In contrast to normal cells, cancer cells typically undergo metabolic reprogramming. Studies have shown that oncogenes play an important role in this metabolic reprogramming. CD38 is a multifunctional transmembrane protein that is expressed abnormally in a variety of tumor types. To investigate the effect and possible mechanism of CD38 in cervical cancer cells and to provide a new therapeutic target for the treatment of cervical cancer, the present study identified that CD38 is involved in regulating cell metabolism in cervical cancer cells. Liquid chromatography-tandem mass spectrometry and bioinformatic analyses revealed that differentially abundant proteins in CD38-overexpressed cervical cancer cells (CaSki-CD38 and HeLa-CD38) are predominantly involved in glycolytic pathways, oxidative phosphorylation and the NAD/NADH metabolic process. Further experiments using an ATP test kit and lactate test kit revealed that CD38 promotes glucose consumption, increases lactate accumulation and increases ATP production. In addition, CD38 increases the phosphorylation of phosphatidylserine/threonine
\end{abstract}

Correspondence to: Professor Yanhong Zhou, Department of Oncology, Xiangya Hospital, Central South University, 88 Xiangya Road, Changsha, Hunan 410008, P.R. China

E-mail: zhouyanhong@csu.edu.cn

Dr Gengqiu Luo, Department of Pathology, Xiangya Hospital, Basic School of Medicine, Central South University, 88 Xiangya Road, Changsha, Hunan 410008, P.R. China

E-mail: luogengqiu@csu.edu.cn

*Contributed equally

Abbreviations: AKT, Akt serine/threonine kinase; mTOR, mammalian target of rapamycin; LDH-A, lactate dehydrogenase A; ATP5H, ATP synthase peripheral stalk subunit D; KEGG, Kyoto Encyclopedia of Genes and Genomes; PI3K, phosphatidylinositol4,5-bisphosphate 3-kinase

Key words: CD38, cervical cancer, cell metabolism, PI3K/AKT/mTOR kinase (AKT), mechanistic target of rapamycin (mTOR) and phosphatidylinositol-4,5-bisphosphate 3-kinase (PI3K), which play a key role in tumor metabolism. Furthermore, it was found that the energy metabolism of cervical cancer cells was inhibited following treatment with the mTOR inhibitor rapamycin. In conclusion, the results of the present study suggested that CD38 regulates the metabolism of cervical cancer cells by regulating the PI3K/AKT/mTOR pathway, which may be a candidate target for the treatment of cervical cancer.

\section{Introduction}

Metabolic reprogramming of cancer cells has become a hot topic in cancer research $(1,2)$. In 1924, Otto Warburg proposed that cancer cells rely predominantly on aerobic glycolysis rather than the more efficient oxidative phosphorylation of mitochondria to produce ATP, even when there is sufficient oxygen supply. The use of aerobic glycolysis leads to an increase in both glucose uptake and lactate production in cancer cells and is termed the Warburg Effect $(3,4)$. Glucose uptake and the demand for metabolic intermediates increases significantly in cancer cells to support rapid cell growth (5). Previously, it was considered that mitochondrial dysfunction in tumor cells leads to a significant decrease of ATP production, thus resulting in a compensatory increase of glycolysis (6-9). However, to the best of our knowledge, the definitive mechanism of the Warburg Effect and how it affects biosynthesis in tumor cells remain unknown. With the development of modern biotechnology, researchers found that in addition to aerobic glycolysis, other metabolic pathways, such as the Krebs cycle $(10,11)$, fatty acid metabolism (12), glutamine metabolism (13-15) and the pentose-phosphate pathway (16), are abnormally regulated in tumor cells. In addition, some studies considered that the aberrant expression of oncogenes and tumor suppressor genes leads to metabolic reprogramming in tumor cells (17-22).

CD38 has dual activities as a ADP-ribosyl cyclase and cyclic ADP-ribose hydrolase $(23,24)$. CD38 is expressed in a variety of cells and regulates diverse activities, such as signal transduction (23), cell adhesion (25), cyclic ADP-ribose synthesis (26), and cell differentiation and activation (27). $\mathrm{CD} 38$ is also involved in regulating mitochondria functions $(28,29)$. Our previous study demonstrated that CD38 
could promote cell proliferation and inhibit cell apoptosis, probably by regulating mitochondrial function (30). We also identified that CD38 is highly expressed in cervical cancer and is associated with the phosphatidylinositol-4,5-bisphosphate 3-kinase (PI3K)/Akt serine/threonine kinase (AKT) signaling pathway. This indicates that CD38 plays an important role in the energy metabolism of cancer cells and is also closely associated with cervical cancer. However, the detailed role and mechanism of CD38 in the carcinogenesis of cervical cancer remains unclear.

The present study aimed to investigate the potential mechanism of CD38 in cervical cancer cells. First, liquid chromatography-tandem mass spectrometry (LC-MS/MS) technology was used to screen for proteins that were differentially abundant in response to CD38 overexpression. Subsequently, the effect of CD38 on key molecules in the $\mathrm{PI} 3 \mathrm{~K} / \mathrm{AKT} / \mathrm{mechanistic}$ target of rapamycin (mTOR) signaling pathway was detected. The effects of CD38 on ATP, lactic acid and other metabolites in cervical cancer cells were also analyzed. To clarify whether CD38 could promote cervical cancer through the PI3K/AKT/mTOR signaling pathway, cells were treated with the mTOR inhibitor rapamycin, and the functional changes induced by CD38 after blocking the $\mathrm{PI} 3 \mathrm{~K} / \mathrm{AKT} / \mathrm{mTOR}$ signaling pathway were analyzed. The results demonstrated that CD38 is involved in cellular energy metabolism via activating the PI3K/AKT/mTOR signaling pathway in cervical cancer cells.

\section{Materials and methods}

Cell lines and cell culture conditions. The cervical cancer cell lines CaSki and HeLa were maintained in the Molecular Genetics Laboratory (Central South University, Changsha, China). Cervical cancer cells were cultured in Roswell Park Memorial Institute (RPMI)-1640 medium containing 10\% fetal bovine serum (FBS; both from Gibco; Thermo Fisher Scientific, Inc.) with $5 \% \mathrm{CO}_{2}$ at $37^{\circ} \mathrm{C}$. The CD38-overexpressing cell lines (CaSki-CD38 and HeLa-CD38) and the control cell lines (CaSki-vector and HeLa-vector) were transfected with the CD38-overexpressing plasmid pEGFP-N1-CD38 and the control plasmid pEGFP-N1 using Lipofectamine 2000 (Invitrogen; Thermo Fisher Scientific, Inc.), according to the manufacturer's protocol, as described previously $(30,31)$. The transfected cell lines were grown in RPMI-1640 supplemented with $10 \%$ FBS and G418 $(500 \mu \mathrm{g} / \mathrm{ml})$. Following 3 weeks, the stable cells were used for subsequent experiments.

Protein extraction and digestion. Protein extraction and digestion were performed as previously described (32). Briefly, cells were lysed using a protein extraction buffer consisting of $50 \mathrm{nM}$ Tris (pH 7.4), $150 \mathrm{mM} \mathrm{NaCl}, 1 \%$ Triton X-100, $1 \%$ sodium deoxycholate, $0.1 \%$ SDA and sodium orthovanadate, sodium fluoride, EDTA, leupeptin supplemented with $1 \mathrm{X}$ halt protease inhibitor cocktail (CWBio) and $1 \mathrm{X}$ halt phosphatase inhibitor cocktail (BestBio). The protein concentration was estimated using the bicinchoninic acid (BCA) method using a Micro BCA ${ }^{\mathrm{TM}}$ Protein assay kit (Thermo Fisher Scientific, Inc.). Then, cell lysates (50 $\mu \mathrm{g}$ of each sample) were loaded onto $10 \%$ SDS-PAGE gels and separated electrophoretically at 80 volts for $40 \mathrm{~min}$ and then 120 volts for $60 \mathrm{~min}$
(PowerPac Universal; Bio-Rad Laboratories, Inc.). Protein bands were visualized using Coomassie brilliant blue G-250 (Sigma-Aldrich; Merck KGaA) and excised from the gel into eight slices. The proteins were destained using $15 \mathrm{mM}$ $\mathrm{K}_{4} \mathrm{Fe}(\mathrm{CN})_{6}$, and then $50 \mathrm{mM}$ sodium thiosulfate and $1.25 \mu \mathrm{g}$ trypsin (1:20 enzyme/substrate ratio) were added to each slice and in-gel-digestion was performed at $37^{\circ} \mathrm{C}$ overnight for $\sim 16 \mathrm{~h}$. The generated peptides were extracted by sonication (15 min, with ice cooling) from the gel pieces in $20 \mu 150 \%$ acetonitrile in $0.1 \%$ formic acid, twice. Following extraction, the peptides were dried using vacuum centrifugation at room temperature for $30 \mathrm{~min}$ to ensure the complete removal of acetonitrile and reconstituted in $20 \mu 10.1 \%$ formic acid.

LC-MS/MS analysis of peptides. LC-MS/MS analysis was performed as previously described (32). Briefly, peptides were diluted using $0.1 \%$ formic acid. Then, peptides were pre-concentrated. The analytes were transferred to the analytical column and separated using a binary system. The mass spectrometer was operated in the data-dependent mode. Normalized collision energy was set to $35 \%$ and an isolation width of $2 \mathrm{~m} / \mathrm{z}$ was chosen.

Protein identification and quantification. Protein identification and quantification were performed as previously described $(32,33)$. Briefly, proteins were identified using Proteome Discoverer 1.4 software (Thermo Fisher Scientific, Inc.). Thermo raw files were imported and used to conduct a search of the UniProt proteomes-Homo sapiens database (UP000005640; https://www.uniprot.org/taxonomy/960). For database searches, mass tolerances were set to $10 \mathrm{ppm}$ and $0.8 \mathrm{Da}$ for precursor and fragment ions, respectively. Peptides identified with false discovery rates $<1 \%$ (q-value $<0.01$ ) were discarded. A common contaminants database was also included for quality control. Proteins that met the following criteria were considered differentially expressed proteins: i) proteins had $\geq 2$ peptides with $\geq 95 \%$ confidence; ii) proteins were considered downregulated when the protein levels demonstrated an average fold-change $\leq 0.5$ in the LC-MS/MS analyses; and iii) proteins were considered upregulated when the protein levels demonstrated an average fold-change $\geq 2$ in the LC-MS/MS analyses (33).

Measurement of glucose concentration. Cells were trypsinized and inoculated into 6 -well cell culture plates ( $1 \times 10^{6}$ cells/well), and then incubated at $37^{\circ} \mathrm{C}$ in the presence of $5 \% \mathrm{CO}_{2}$. Following 24-48 h, when the density of cells had reached $\sim 80 \%$, the culture medium supernatant was transferred into a new centrifuge tube and centrifuged at $1,000 \times \mathrm{g}$ for $5 \mathrm{~min}$ at $4^{\circ} \mathrm{C}$ to remove insoluble materials. The supernatant was transferred into specific tubes to detect the glucose concentration using an ADVIA 1650 automatic biochemical analyzer (Siemens AG). Meanwhile, the cells in the culture plate were trypsinized, washed with cold 1x PBS solution and placed in microcentrifuge tubes. Following ultrasonication on ice for $3 \mathrm{~min}$, the samples were centrifuged at $12,000 \mathrm{x}$ g for $20 \mathrm{~min}$ at $4^{\circ} \mathrm{C}$. The supernatant was transferred into specific tubes to detect the intracellular glucose concentration using the ADVIA 1650 automatic biochemical analyzer (Siemens AG). All values were normalized on the basis of cell number. 


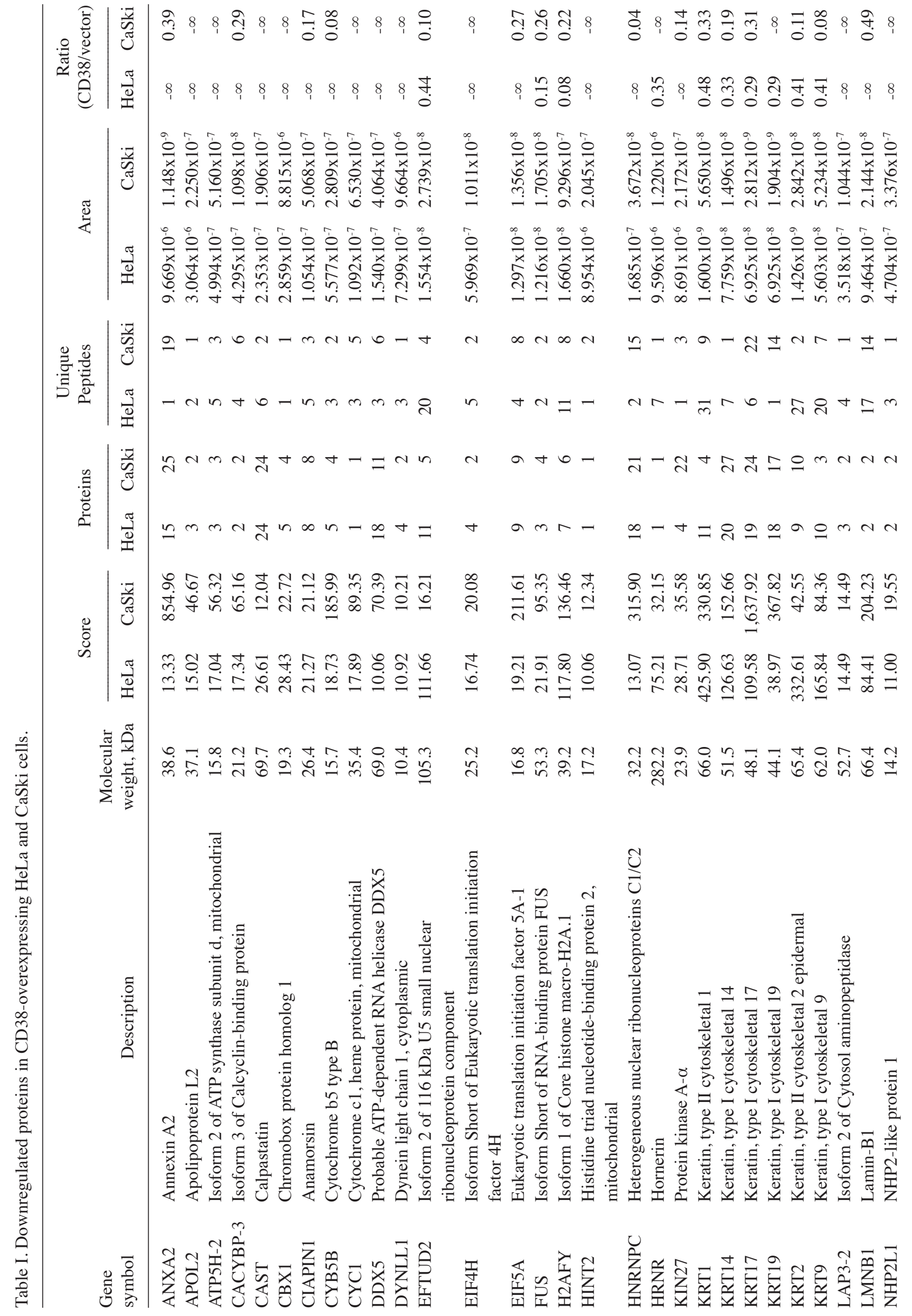




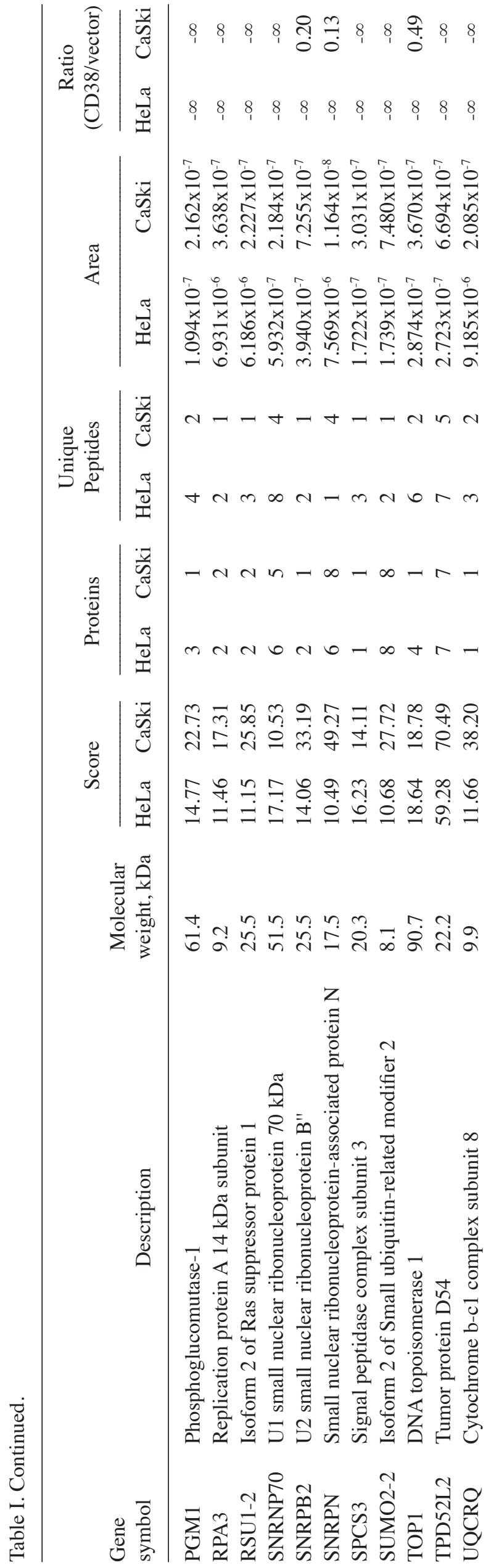

Measurement of the cellular ATP concentration. The cellular ATP concentration was measured using an ATP detection assay kit (catalog no. S0026; Beyotime Institute of Biotechnology), according to the manufacturer's protocol. Cells were trypsinized, seeded into 6 -well cell culture plates $\left(1 \times 10^{6}\right.$ cells/well $)$ and incubated at $37^{\circ} \mathrm{C}$ in the presence of $5 \% \mathrm{CO}_{2}$. Following $24 \mathrm{~h}$, when the cell density reached $\sim 80 \%$, the culture medium was aspirated from the plate and $200 \mu \mathrm{l}$ ATP lysis buffer was added into each well. The lysis buffer and cells were pipetted repeatedly to homogenize the cells on ice for $5 \mathrm{~min}$. The cell lysate was transferred into new pre-cooled tubes and centrifuged at $12,000 \mathrm{x}$ g for $15 \mathrm{~min}$ at $4^{\circ} \mathrm{C}$. The supernatant was transferred into new pre-cold tubes and kept on ice. The ATP standard buffer and ATP detection buffer were prepared. The ATP detection buffer was added into the wells of a 96-well plate $(100 \mu \mathrm{l} /$ well) and kept at room temperature for $5 \mathrm{~min}$. The samples or ATP standard buffer were then added into the wells (20 $\mu \mathrm{l} /$ well $)$ and incubated in the dark for $5 \mathrm{~min}$ at room temperature. The luminescence emitted by the samples was detected using a Paradigm Detection Platform (Beckman Coulter, Inc.). The concentration of cellular ATP (nmol/mg) was calculated based on a standard curve. All values were normalized to the protein concentration.

Measurement of the lactate concentration. The lactate concentration was detected using a Lactate assay kit (catalog no.MAK064; Sigma-Aldrich;MerckKGaA), according to the manufacturer's protocol. Briefly, cells were trypsinized and seeded into 6 -well cell culture plates $\left(1 \times 10^{6}\right.$ cells/well). The cells were incubated at $37^{\circ} \mathrm{C}$ in the presence of $5 \% \mathrm{CO}_{2}$. Following 24-48 h, when the cell density reached $\sim 80 \%$, the culture medium supernatant was transferred into new centrifuge tubes, and centrifuged at $12,000 \mathrm{x}$ g for $20 \mathrm{~min}$ at $4^{\circ} \mathrm{C}$ to remove insoluble materials. The supernatant was transferred into $10 \mathrm{kDa}$ cut-off spin filters to deproteinize the samples to remove enzymes that may consume lactate. The filtrate was transferred into new tubes and kept on ice to detect the lactate concentration in the medium. Meanwhile, cells in the culture plate were digested and washed with cold 1x PBS solution and the resuspended cells were placed in microcentrifuge tubes. Following ultrasonication on ice for $3 \mathrm{~min}$, the samples were centrifuged at $12,000 \mathrm{x}$ g for $20 \mathrm{~min}$ at $4^{\circ} \mathrm{C}$. The supernatant was transferred into $10 \mathrm{kDa}$ cut-off spin filters to deproteinize the samples. The filtrate was transferred into new tubes and kept on ice to detect the intracellular lactate concentration. Then, $50 \mu 1$ samples were placed into the wells of a 96-well plate, $50 \mu 1$ Master Reaction mix was added to each sample, and the plate was incubated in the dark for $30 \mathrm{~min}$ at room temperature. The absorbance value at $570 \mathrm{~nm}$ was detected with a microplate reader and analyzed with SoftMAx Pro 6.4 (Beckman Coulter). The lactate concentration was calculated based on a standard curve. All values were normalized on the basis of cell number.

Western blotting analysis. Western blotting was performed as described previously $(30,31)$. The cells were trypsinized and then lysed using RIPA lysate buffer (CWBio). Samples were centrifuged at $12,000 \mathrm{xg}$ for $15 \mathrm{~min}$ at $4^{\circ} \mathrm{C}$ to remove insoluble materials. The protein concentration estimated using the BCA method, and each protein sample $(50 \mu \mathrm{g})$ was electrophoresed 


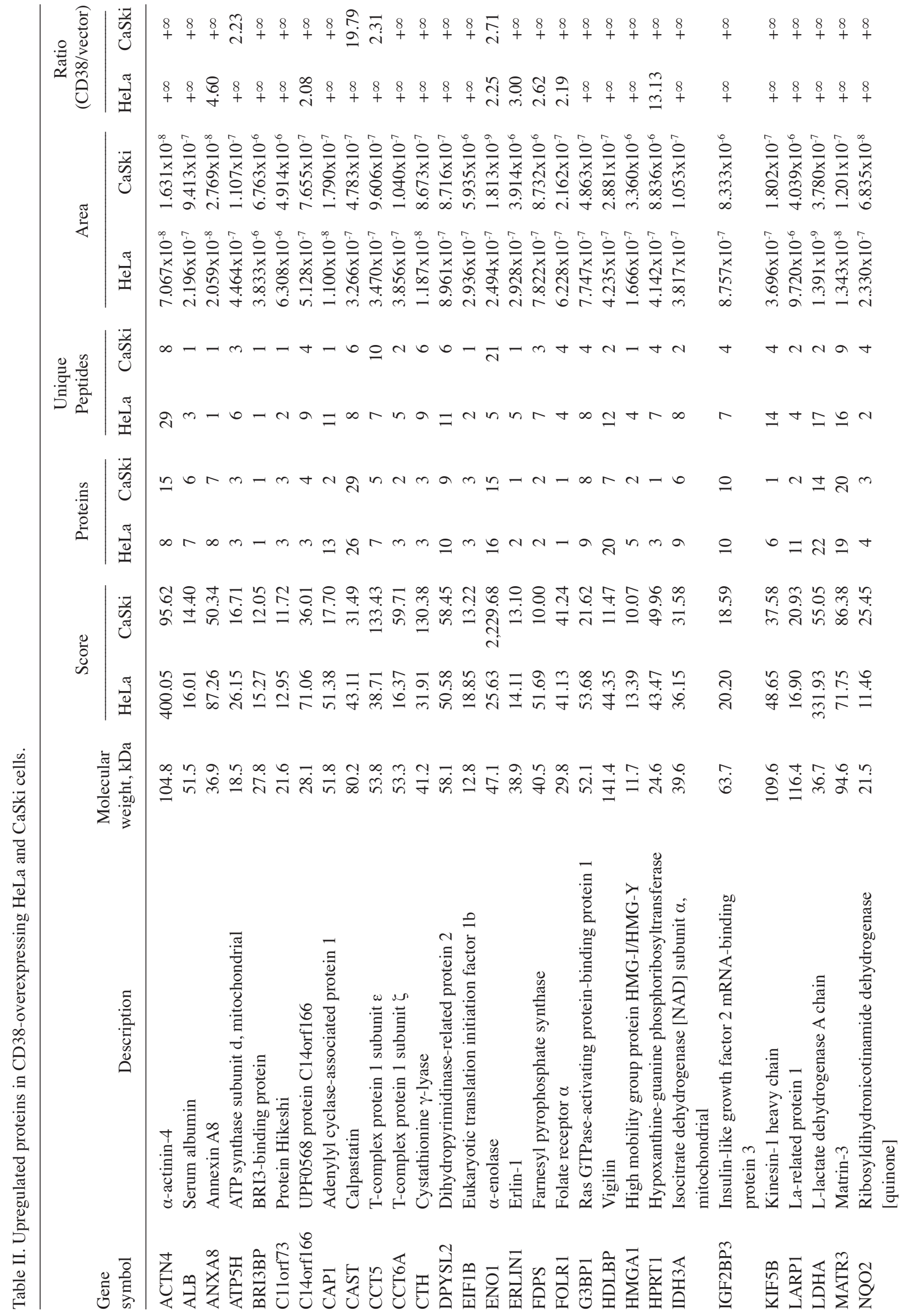




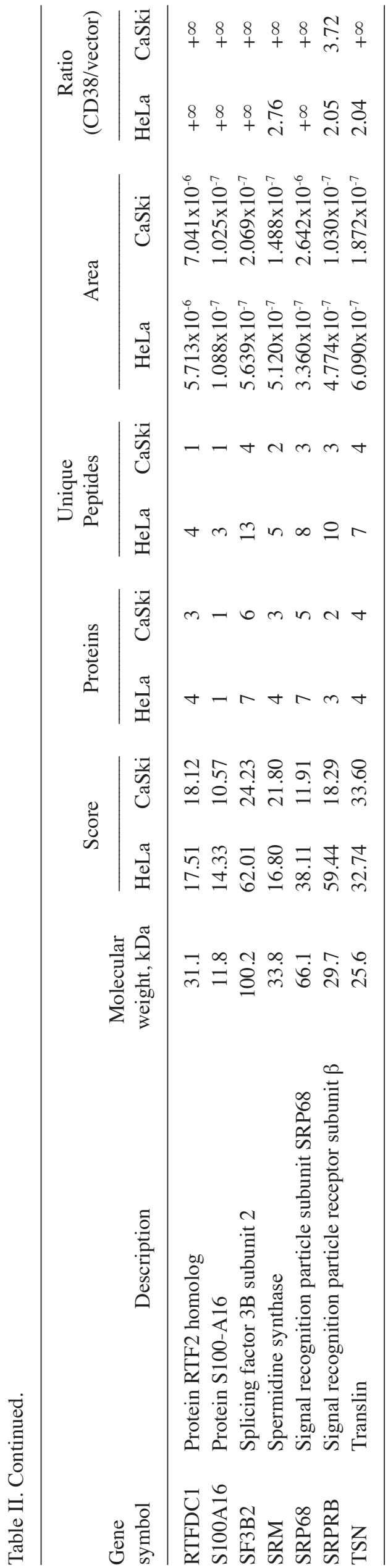

using a $10 \%$ SDS-PAGE gel at 80 volt for $40 \mathrm{~min}$ and then at 120 volt for 60 min (PowerPac Universal; Bio-Rad Laboratories, Inc.). The separated proteins were transferred onto a polyvinylidene fluoride membrane (HyClone; GE Healthcare Life Sciences) at 100 volt for $90 \mathrm{~min}$ and then the membranes were blocked for 1-2 h using 5\% non-fat milk dissolved in PBS-0.1\% Tween 20. The membranes were then incubated overnight with primary antibodies at $4^{\circ} \mathrm{C}$. The following primary antibodies were used: Anti-CD38 (catalog no. YM0122; ImmunoWay Biotechnology Company), anti-3-phosphoinositide dependent protein kinase 1 (catalog no. YT3645; ImmunoWay Biotechnology Company), anti-PI3K P110 (catalog no. YT3709; ImmunoWay Biotechnology Company), anti-AKT (catalog no. YT0173; ImmunoWay Biotechnology Company), anti-phosphorylated (p)-AKT T308 (catalog no. YP0590; ImmunoWay Biotechnology Company), anti-mTOR (catalog no. YT2913; ImmunoWay Biotechnology Company), anti-p-mTOR (catalog no. YP0716; ImmunoWay Biotechnology Company), anti-lactate dehydrogenase A (LDH-A; catalog no. 19987-1-AP; ProteinTech Group, Inc.) and anti-ATP synthase peripheral stalk subunit D (ATP5H; catalog no. YT0406; ImmunoWay Biotechnology Company). These antibodies were stored at $-20^{\circ} \mathrm{C}$, and the dilution used for all antibodies was 1:1,000. The membranes were then washed and incubated with the following horseradish peroxidase-conjugated secondary antibodies for $1 \mathrm{~h}$ at $37^{\circ} \mathrm{C}$ : Anti-rabbit secondary antibody (catalog no. sc-2004; Santa Cruz Biotechnology. Inc.; 1:3,000) and anti-mouse secondary antibody (catalog no. sc-2005; Santa Cruz Biotechnology. Inc.; 1:3,000). The immunoreactive protein bands were then visualized using ECL luminescent liquid (EMD Millipore) and analyzed using Molecular Imager ${ }^{\circledR}$ Gel Dox XR System (Bio-Rad Laboratories). Rabbit anti-GAPDH (catalog no. 2118; Cell Signaling Technology, Inc.; 1:5,000), rabbit anti- $\beta$-actin (catalog no. T0022; Affinity Biosciences; 1:5,000) and rabbit anti- $\beta$-tubulin antibody (catalog no. T0028; Affinity Biosciences; 1:5,000) were used as controls. ImageJ (v 1.51; National Institutes of Health) was used to quantitatively analyze the results.

Clonogenic assay. Cervical cancer cells were transfected with the empty vector and the CD38 overexpression vector and then seeded at a density of 800 cells/well in a 6 -well plate. Following adherence, the cells in the wells were treated with $0.1 \mu \mathrm{M}$ DMSO and $0.1 \mu \mathrm{M}$ rapamycin (catalog no. S1039; Selleck Chemicals) at $37^{\circ} \mathrm{C}$ for $24 \mathrm{~h}$. When the clone was visible to the naked eye, the culture was terminated. The culture medium was discarded and the cells were washed three times with PBS buffer. The cells were treated with paraformaldehyde for $30 \mathrm{~min}$ at room temperature, washed with $1 \mathrm{x}$ PBS, stained with $0.1 \%$ crystal violet for $30 \mathrm{~min}$ at room temperature and washed with tap water. Images were then obtained and the cells were counted.

Cell apoptosis experiment. A Hoechst33342/propidium iodide (PI) double staining kit (catalog no. bb-4131; Bestbio) was used to detect cell apoptosis according to the recommended protocol. The CD38 overexpression vector and the blank vector were transfected into CaSki and HeLa cells. The cells were seeded in 6 -well plates and cultured at $37^{\circ} \mathrm{C}$ with 
A

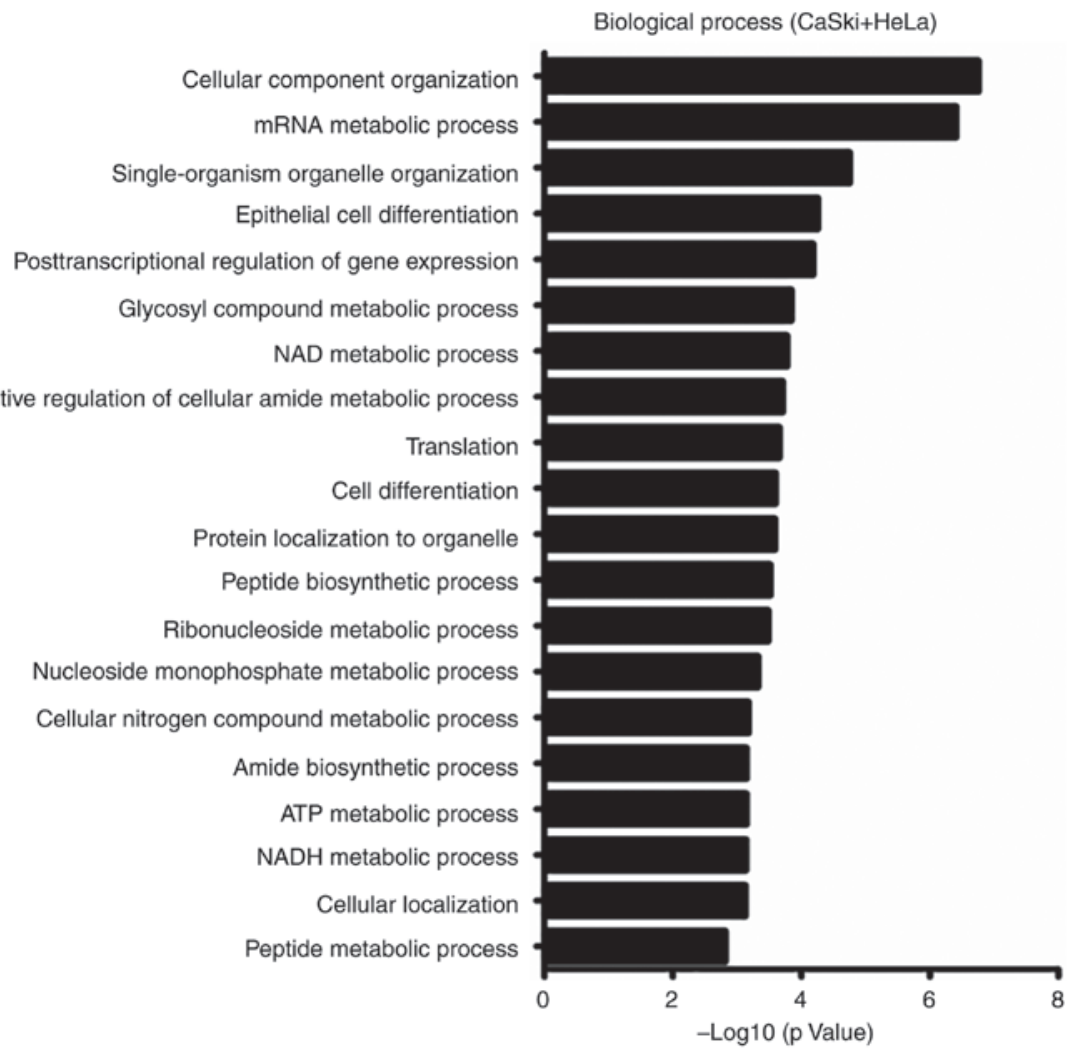

B

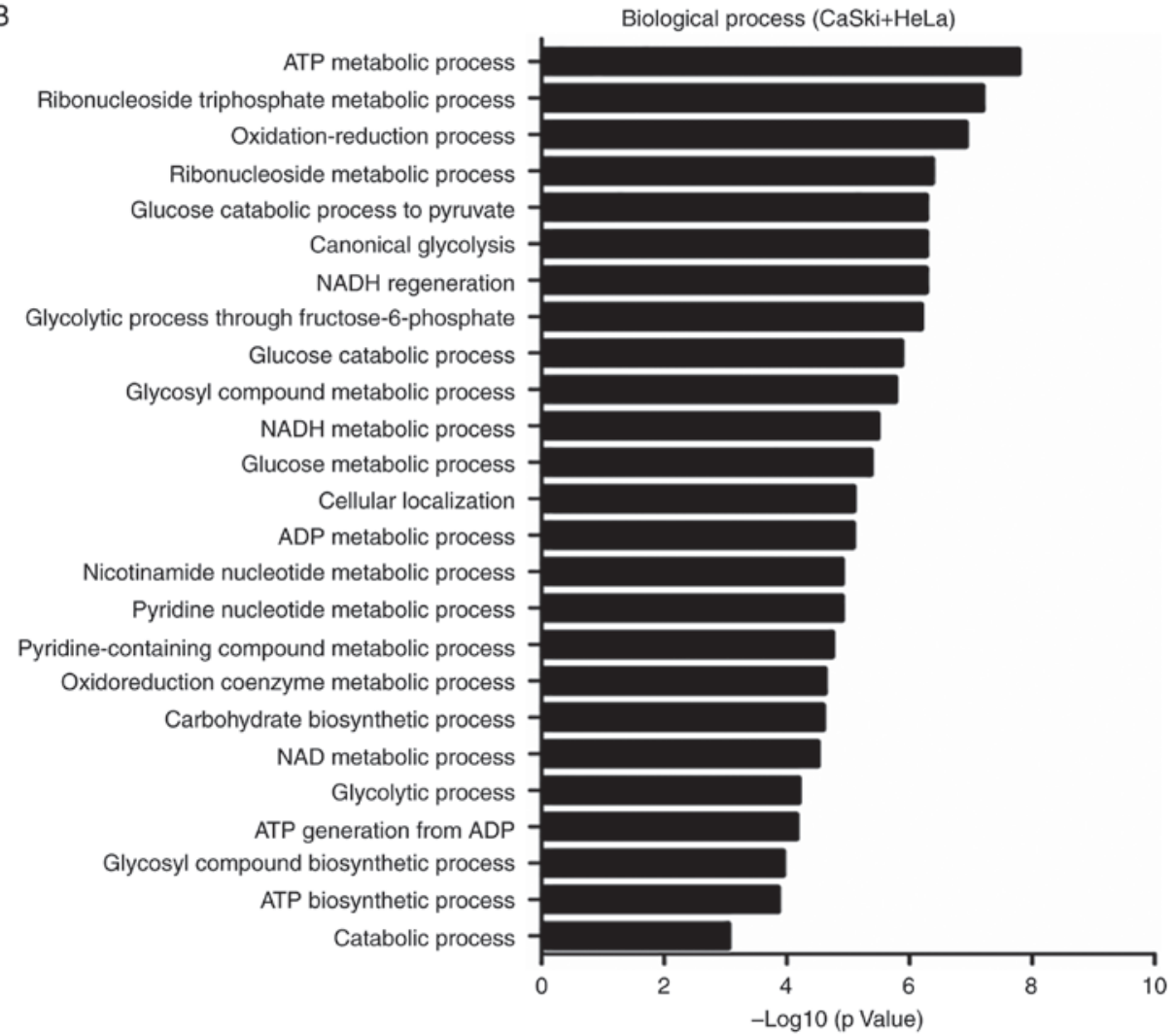

Figure 1. GO analysis of biological processes and KEGG analysis of differentially expressed genes in CD38-overexpressing cervical cancer cells. (A) GO analysis demonstrating the top 20 enriched biological process terms for genes downregulated in CD38-overexpressing CaSki and HeLa cells, ranked by fold-change. (B) The top $25 \mathrm{GO}$ biological process terms for genes upregulated in CD38-overexpressing CaSki and HeLa cells.

$5 \% \mathrm{CO}_{2}$. After adhering to the wall, the cells were treated with DMSO and rapamycin. Following $24 \mathrm{~h}$, the cells were digested with $0.25 \%$ trypsin, collected, and washed twice with PBS.
The cells were resuspended in $0.5-1.0 \mathrm{ml}$ staining buffer, and Hoechst33342 staining solution A (5-10 $\mu \mathrm{l})$ was then added. Following gentle mixing, the cells were incubated at $4^{\circ} \mathrm{C}$ in 

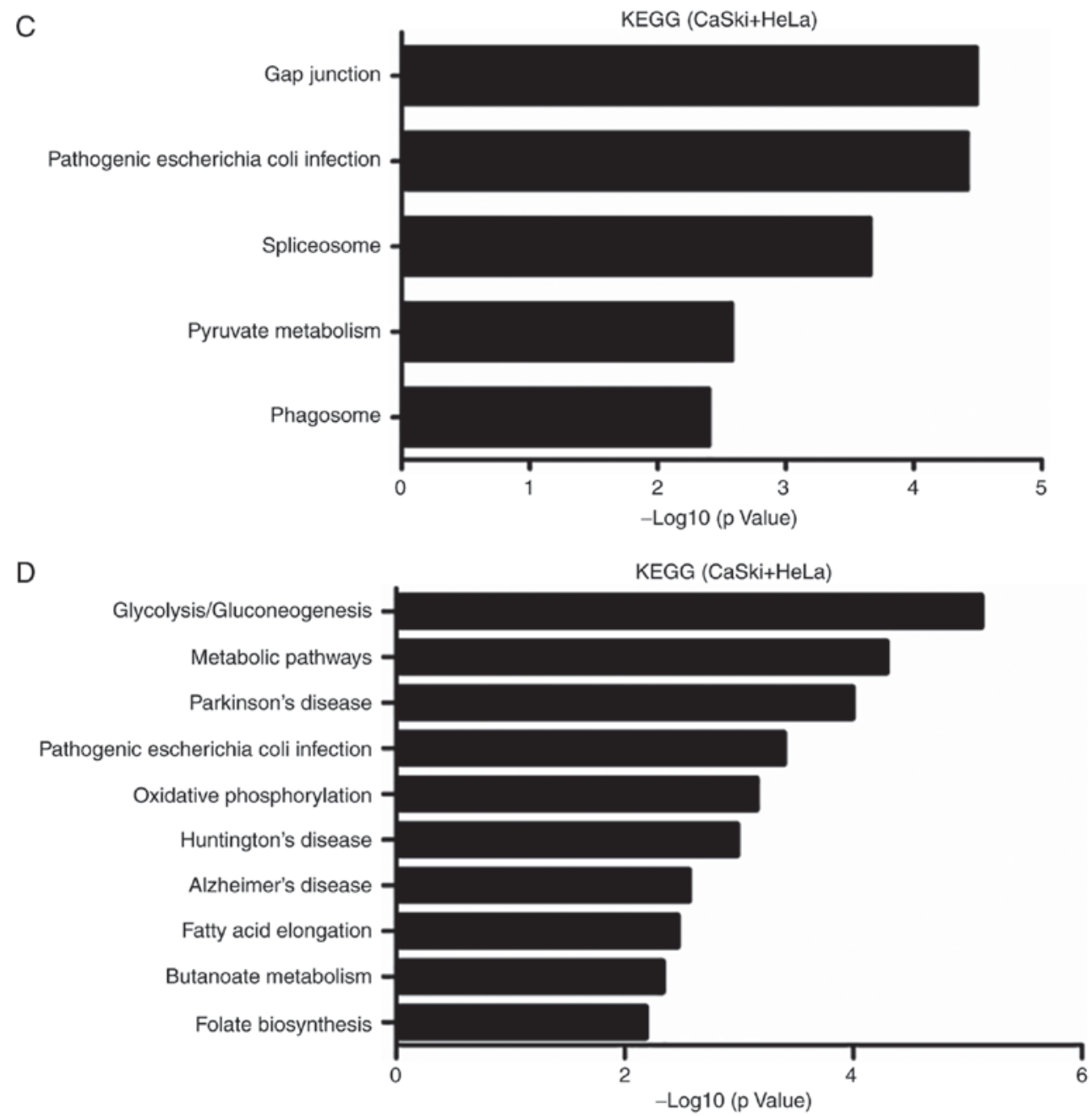

Figure 1. Continued. GO analysis of biological processes and KEGG analysis of differentially expressed genes in CD38-overexpressing cervical cancer cells. (C) KEGG analysis revealed the top five pathways associated with genes downregulated in CD38-overexpressing CaSki and HeLa cells, according to the criterion of fold-change $\geq 2$. (D) KEGG analysis revealed the top ten pathways of genes downregulated in CD38-overexpressing CaSki and HeLa cells, according to the criterion of fold-change $\geq 2$. GO, Gene Ontology; KEGG, Kyoto Encyclopedia of Genes and Genomes.

the dark for $10 \mathrm{~min}$, and 5-10 $\mu \mathrm{l}$ PI was then added. Staining solution B was added $(5-10 \mu 1)$, the samples were gently mixed, and then incubated at $4^{\circ} \mathrm{C}$ in dark for 5-10 min. Finally, the cells were washed with PBS, resuspended in PBS and detected using flow cytometry. Analysis was performed using Summit v5.2 software (Beckman Coulter, Inc.).

Statistical analysis. Data are presented as the mean \pm standard deviation of three independent experiments. Differences in parametric variables were analyzed using ANOVA followed by Student-Newman-Keuls post hoc test, and differences in quantitative variables between groups were analyzed by Kruskal-Wallis followed by Bonferroni's test. Statistical analyses were performed with the EPI Info software (version 3.2.2; www.CDC.gov/epiinfo/). $\mathrm{P}<0.05$ was considered to indicate a statistically significant difference.

\section{Results}

Identification of differentially abundant proteins in CD38-overexpressing cervical cancer cells using LC-MS/MS analysis. Our previous study demonstrated that
CD38 expression is upregulated in cervical cancer. In vitro experiments revealed that CD38 could inhibit the apoptosis of cervical cancer cells and promote their proliferation. The previous results also demonstrated that CD38 affects the intracellular calcium concentration, mitochondrial membrane potential and intracellular reactive oxygen species in cervical cancer cells (30). Therefore, it was speculated that CD38 may be associated with the metabolism of cervical cancer cells.

To investigate if CD38 affects the metabolism of cervical cancer cells, LC-MS/MS technology was first used to screen and identify differentially abundant proteins between CD38-overexpressing cervical cancer cells and the control groups. Proteins were identified using Proteome Discoverer 1.4 software and analyzed by the UniProtKB/Swiss-Prot database. It was identified that 573 proteins were downregulated in CaSki-CD38 cells compared with the control cells and 274 proteins were downregulated in HeLa-CD38 cells compared with the control cells. Among these proteins, 40 proteins were consistently downregulated in both CaSki-CD38 and HeLa-CD38 cells. These 40 overlapping downregulated proteins are listed in Table I. By contrast, 357 proteins were found to be upregulated in CaSki-CD38 

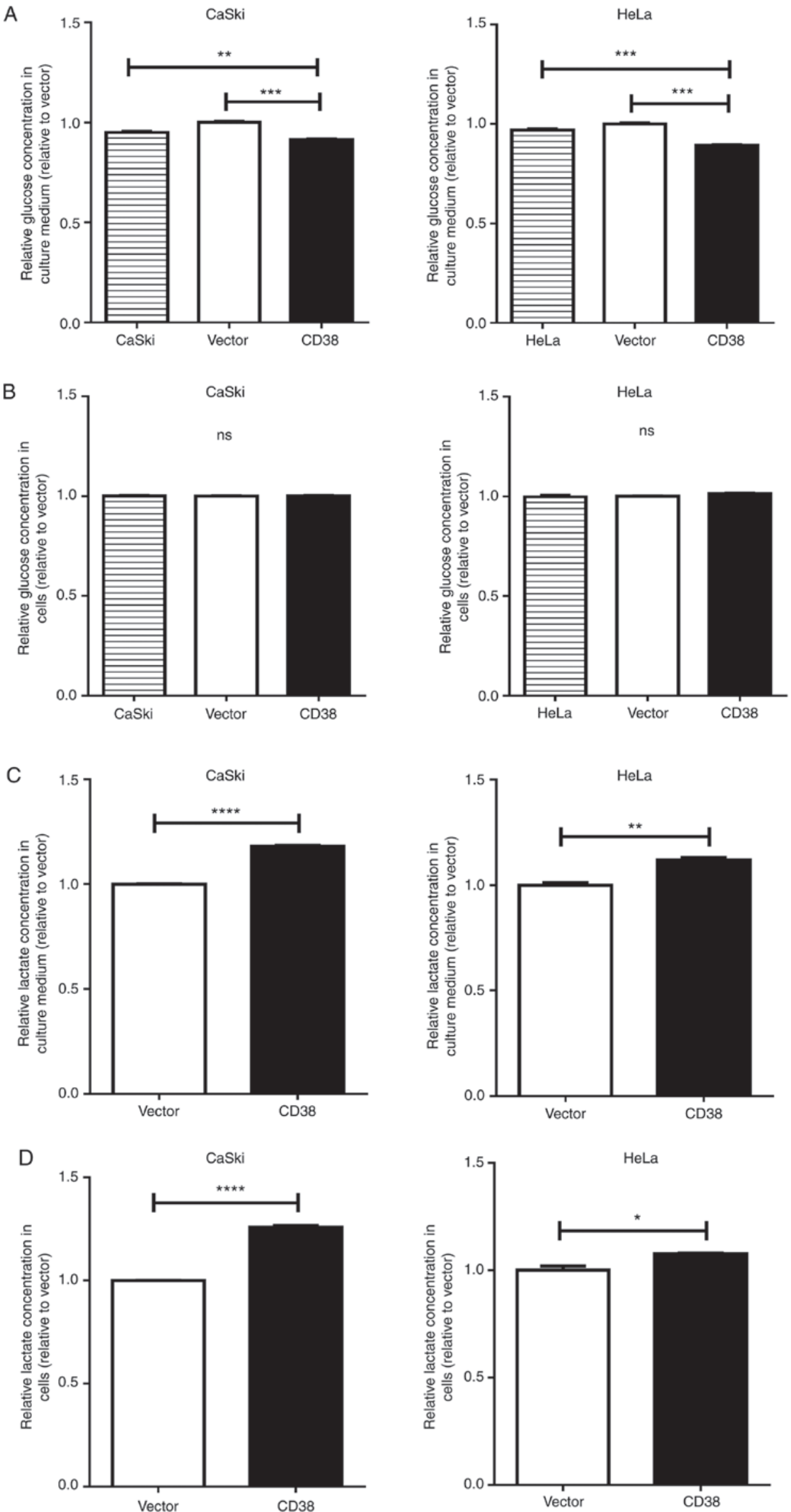

Figure 2. Detection of glucose uptake ability, intracellular ATP and lactic acid concentrations in cervical cancer cells. (A) Glucose concentration in the culture medium and (B) the intracellular glucose concentration in cultured cervical cancer cells. (C) The lactate concentration in the culture medium and (D) the intracellular lactate concentration in cultured cervical cancer cells. All values were normalized on the basis of cell number. 

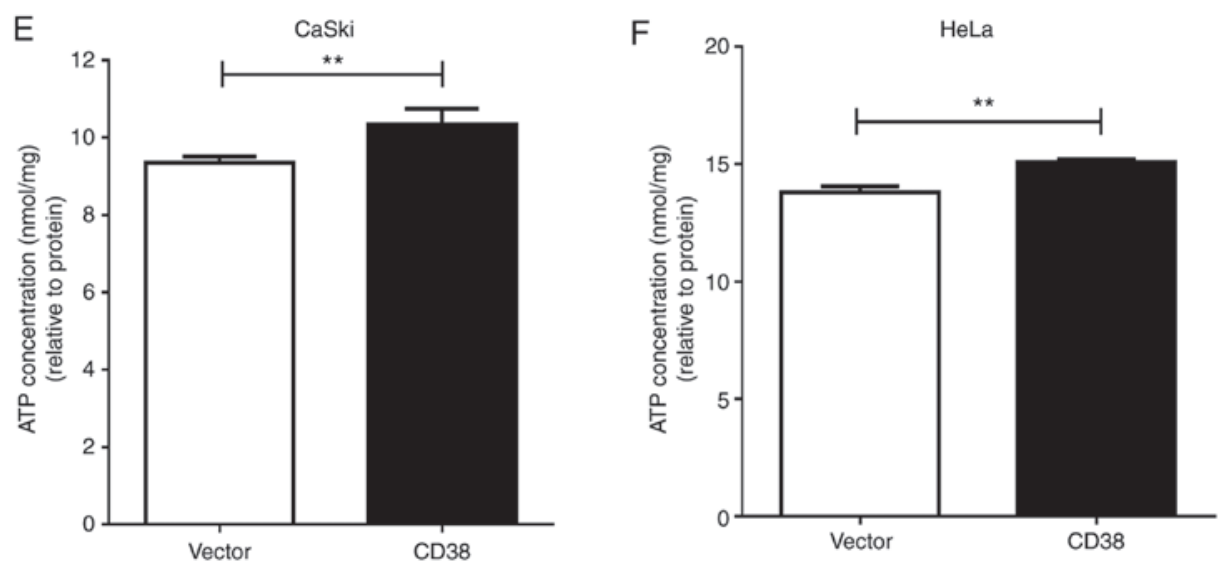

Figure 2. Continued. Detection of glucose uptake ability, intracellular ATP and lactic acid concentrations in cervical cancer cells. CD38 overexpression significantly increased the intracellular ATP concentration in (E) CaSki and (F) HeLa cells. Data are presented as the mean \pm standard deviation of three independent experiments. ${ }^{*} \mathrm{P}<0.05,{ }^{* *} \mathrm{P}<0.01,{ }^{* * *} \mathrm{P}<0.001$ and ${ }^{* * * *} \mathrm{P}<0.0001$. ns, not significant.

cells and 359 proteins were upregulated in HeLa-CD38 cells compared with the control cells. Among these, 36 proteins were consistently upregulated both in CaSki-CD38 and HeLa-CD38 cells. These 36 overlapping upregulated proteins are listed in Table II.

Gene Ontology (GO) analysis of biological processes and Kyoto Encyclopedia of Genes and Genomes (KEGG) analysis of differentially expressed proteins in CD38-overexpressing cervical cancer cells. The results of the LC-MS/MS analysis revealed that ATP5H-2, cytochrome B5 type B (CYB5B), cytochrome $\mathrm{C} 1$ (CYC1) and other protein molecules were upregulated in CD38-overexpressing cervical cancer cells, while BRI3 binding protein (BRI3BP) and other protein molecules were downregulated. To further analyze the biological processes and signaling pathways that involve these differentially abundant proteins, GO and KEGG analyses were performed. As presented in Fig. 1, the differentially abundant proteins were annotated to be involved in the following biological processes: 'Glucose catabolic process to pyruvate', 'oxidation-reduction process', 'glucose metabolic process', 'nucleoside monophosphate metabolic process', 'glycosyl compound metabolic process', 'NAD/NADH metabolic process' and 'ATP/ADP metabolic process'. This indicates that these proteins are predominantly involved in glycolytic pathways, oxidative phosphorylation and NAD/NADH metabolic processes. KEGG analysis demonstrated that CD38 overexpression was associated with 'pyruvate metabolism', 'glycolysis/gluconeogenesis', 'metabolic pathways' and 'fatty acid elongation'. Thus, it can be suggested that CD38 is involved in regulating cellular energy metabolism in cervical cancer cells.

CD38 increases glucose uptake, ATP production, and lactic acid accumulation in cervical cancer cells. To test the hypothesis that that CD38 is involved in regulating cellular energy metabolism in cervical cancer cells, the effects of CD38 overexpression on glucose uptake, intracellular ATP production and intracellular lactic acid concentration in cervical cancer cells were investigated. The glucose concentration in the culture medium was significantly decreased in CaSki-CD38 and HeLa-CD38 cells compared with vector-transfected cells $(\mathrm{P}=0.0002$ and $\mathrm{P}<0.0001$, respectively; Fig. $2 \mathrm{~A})$. The intracellular glucose concentration showed no significant difference between CD38-overexpressing cervical cancer cells and the control groups (Fig. 2B). It was speculated that, to a certain extent, CD38 promotes glucose consumption in cervical cancer cells. The lactate concentration in the culture medium was significantly increased in CaSki-CD38 and HeLa-CD38 cells compared with vector-transfected cells $(\mathrm{P}<0.0001$ and $\mathrm{P}=0.0021$, respectively; Fig. 2C). The intracellular lactate concentration was also significantly increased in CaSki-CD38 and HeLa-CD38 compared with vector-transfected cells $(\mathrm{P}<0.0001$ and $\mathrm{P}=0.019$; Fig. 2D).

Further research revealed that CD38 overexpression significantly increased the intracellular ATP concentration in CaSki cells $(\mathrm{P}=0.001$; Fig. $2 \mathrm{E})$ and HeLa cells $(\mathrm{P}=0.003$; Fig. $2 \mathrm{~F})$. These results suggest that $\mathrm{CD} 38$ is involved in regulating the glucose concentration and can lead to an accumulation of lactate in cervical cancer cells.

CD38 affects cellular energy metabolism by activating the PI3K/AKT/mTOR signaling pathway in cervical cancer cells. To investigate the possible effects and mechanism of CD38 on the energy metabolism in cervical cancer cells, key molecules of the PI3K/AKT/mTOR signaling pathway were investigated in CaSki and HeLa cells. In CaSki cells, CD38 overexpression significantly increased the expression levels of PI3K, PDK1, ATP5H and LDHA. CD38 overexpression also significantly increased the ratios of $\mathrm{p}-\mathrm{AKT} / \mathrm{AKT}$ and $\mathrm{p}-\mathrm{mTOR} / \mathrm{mTOR}$ (Fig. 3A). These results suggest that CD38 had a significant effect on the phosphorylation of AKT and mTOR. To confirm that CD38 is involved in the regulation of energy metabolism in cervical cancer cells via the PI3K/AKT/mTOR signaling pathway, the cervical cancer cells were treated with rapamycin. Following treatment with DMSO, the expression levels of LDHA and ATP5H were significantly higher in CaSki-CD38 cells compared with the control CaSki-vector cells. In addition, the p-mTOR/mTOR ratio was significantly higher in CaSki-CD38 cells compared with the control cells following treatment with DMSO. After treatment with rapamycin, the expression levels of LDHA and ATP5H were significantly 
A
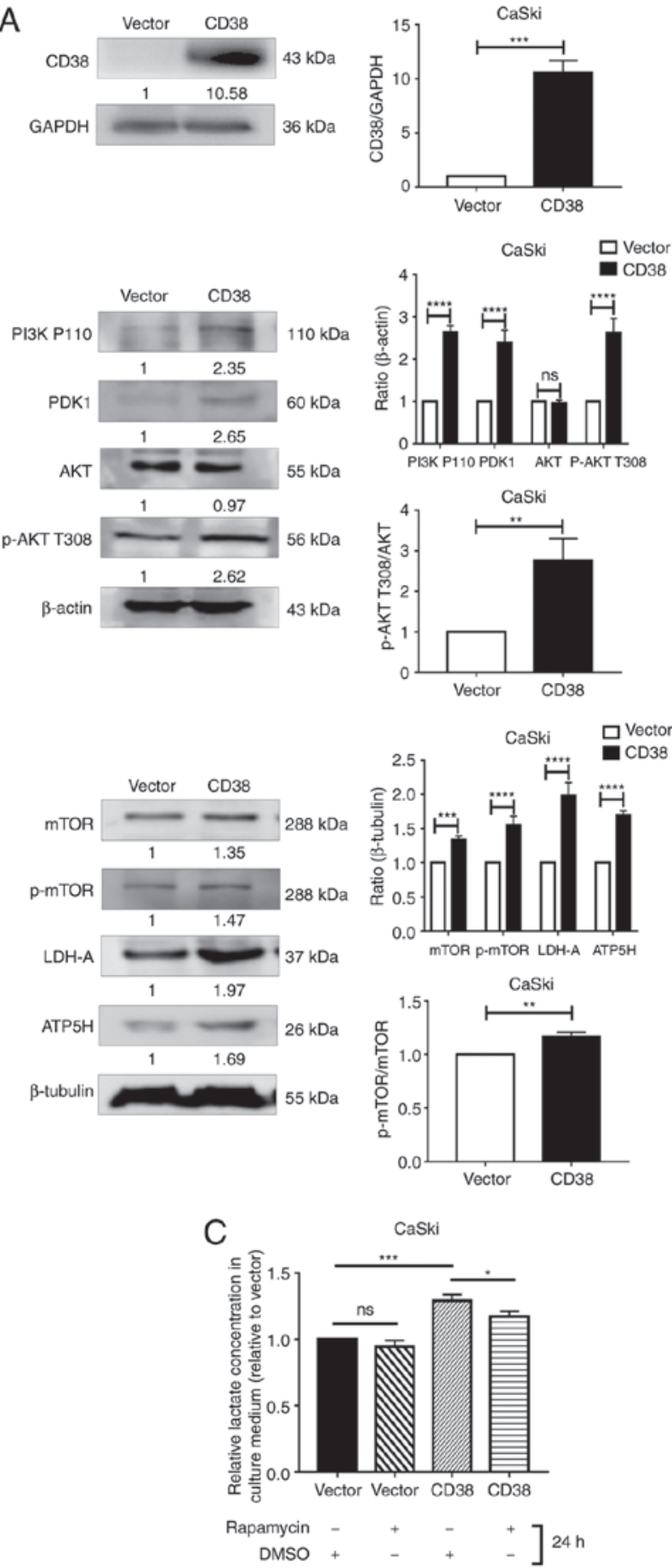

B
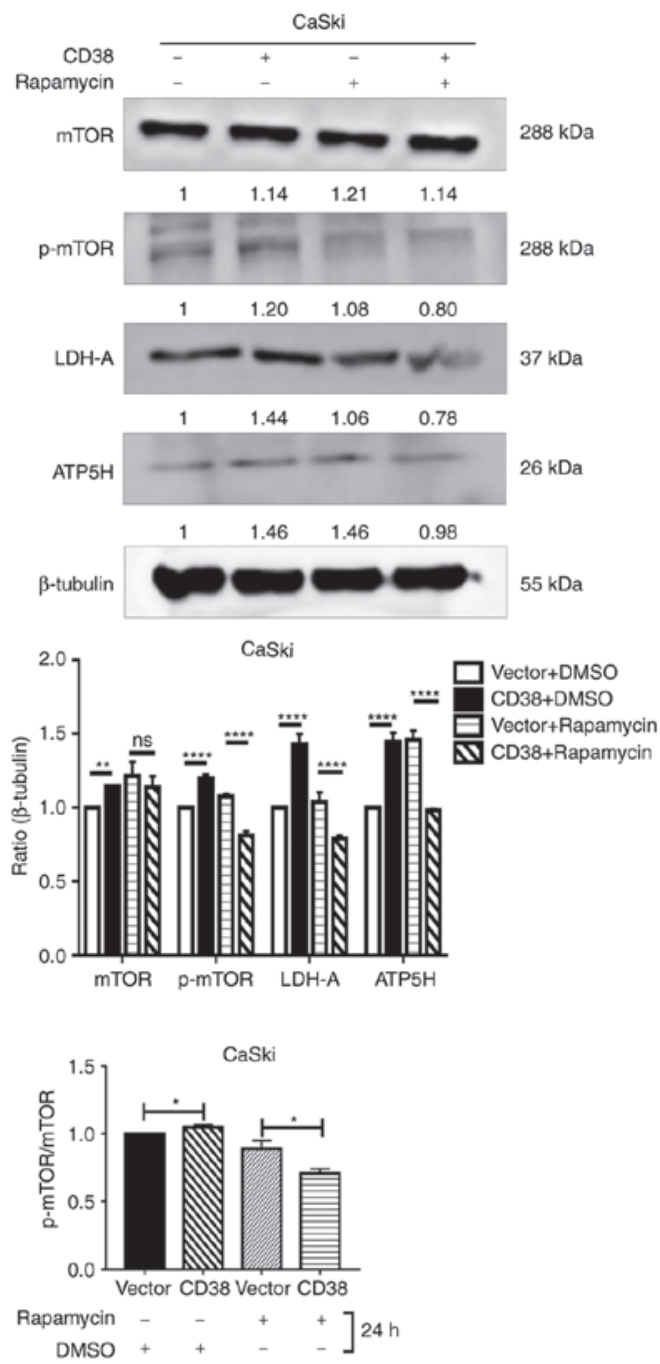

D

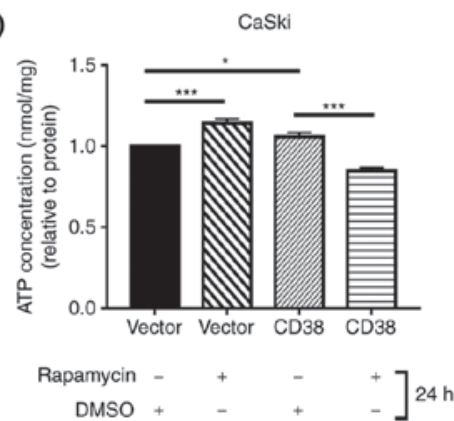

Figure 3. Detection of the levels of key molecules in the PI3K/AKT/mTOR signaling pathway in CaSki cells. (A) Western blot analysis of PDK1, PI3K P110, AKT, p-AKT T308, p-AKT S473, m-TOR, p-mTOR, LDH-A and ATP5H following CD38 overexpression. Images are representative of three independent experiments. (B) Western blotting analysis of m-TOR, p-mTOR, LDH-A and ATP5H in cells treated with rapamycin for $24 \mathrm{~h}$. (C) The lactate concentration in the culture medium of CaSki cells treated with rapamycin for $24 \mathrm{~h}$. All values were normalized on the basis of cell number. (D) ATP concentration in the culture medium of CaSki cells treated with rapamycin for $24 \mathrm{~h}$. All values were normalized on the basis of cell number. Data are presented as the mean \pm standard deviation of three independent experiments. ${ }^{*} \mathrm{P}<0.05,{ }^{* *} \mathrm{P}<0.01,{ }^{* * *} \mathrm{P}<0.001$ and ${ }^{* * * *} \mathrm{P}<0.0001$. ns, not significant; PI3K, phosphatidylinositol-4,5-bisphosphate 3-kinase; PDK1, phosphoinositide dependent protein kinase 1; AKT, Akt serine/threonine kinase; mTOR, mammalian target of rapamycin; LDH-A, lactate dehydrogenase A; ATP5H, ATP synthase peripheral stalk subunit D; p-, phosphorylated.

lower in CaSki-CD38 cells compared with the control CaSki-vector cells. In addition, the p-mTOR/mTOR ratio was significantly decreased (Fig. 3B). These results suggest that rapamycin can block the effects of CD38 on LDHA, ATP5H and mTOR. ATP5H and LDH-A affect the concentration of ATP and lactic acid in CaSki cells (34). To determine whether rapamycin alters the effects of CD38 on ATP and lactic acid in CaSki cells, the concentration of ATP and lactic acid were measured in rapamycin-treated cells. The results demonstrated that rapamycin could significantly reverse the effects of CD38 overexpression on ATP and lactic acid levels in CaSki cells (Fig. 3C and D). 

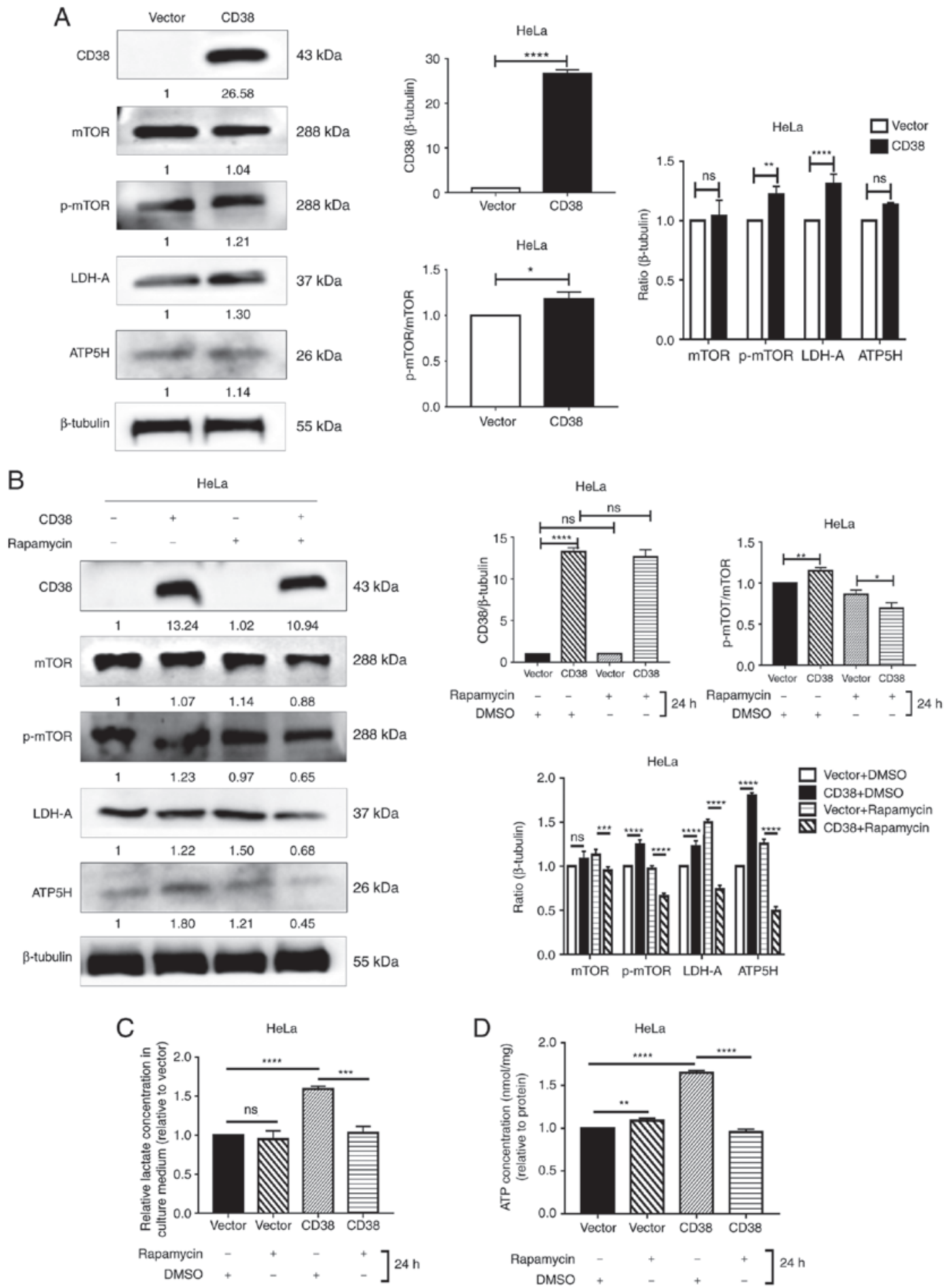

Figure 4. Detection of the levels of key molecules in the PI3K/AKT/mTOR signaling pathway in HeLa cells. (A) Western blotting analysis of mTOR, p-mTOR, LDH-A and ATP5H following CD38 overexpression in HeLa cells. Images are representative of three independent experiments. (B) Western blotting analysis of m-TOR, p-mTOR, LDH-A and ATP5H in HeLa cells treated with rapamycin for $24 \mathrm{~h}$. (C) The lactate concentration in the culture medium of HeLa cells treated with rapamycin for $24 \mathrm{~h}$. All values were normalized on the basis of cell number. (D) ATP concentrations in the culture medium of HeLa cells treated with rapamycin for $24 \mathrm{~h}$. All values were normalized on the basis of cell number. Data are presented as the mean \pm standard deviation of three independent experiments. ${ }^{*} \mathrm{P}<0.05,{ }^{* *} \mathrm{P}<0.01,{ }^{* * *} \mathrm{P}<0.001$ and ${ }^{* * * * *} \mathrm{P}<0.0001$. ns, not significant; mTOR, mammalian target of rapamycin; LDH-A, lactate dehydrogenase A; ATP5H, ATP synthase peripheral stalk subunit D; p-, phosphorylated.

Furthermore, the protein levels of mTOR, p-mTOR, LDH-A and ATP5H were detected in HeLa cells. In HeLa cells, CD38 overexpression significantly increased the levels of p-mTOR and LDHA, but no difference was observed for total mTOR or ATP5H. However, CD38 significantly increased the ratio of p-mTOR/total mTOR, indicating that CD38 has a significant effect on the phosphorylation of mTOR (Fig. 4A). Similarly, following treatment with DMSO, the expression levels of LDHA and ATP5H were significantly higher in HeLa-CD38 cells compared with the control HeLa-vector cells. In addition, the ratio of p-mTOR/mTOR was increased in HeLa-CD38 cells. Following treatment with rapamycin, the expression levels of 


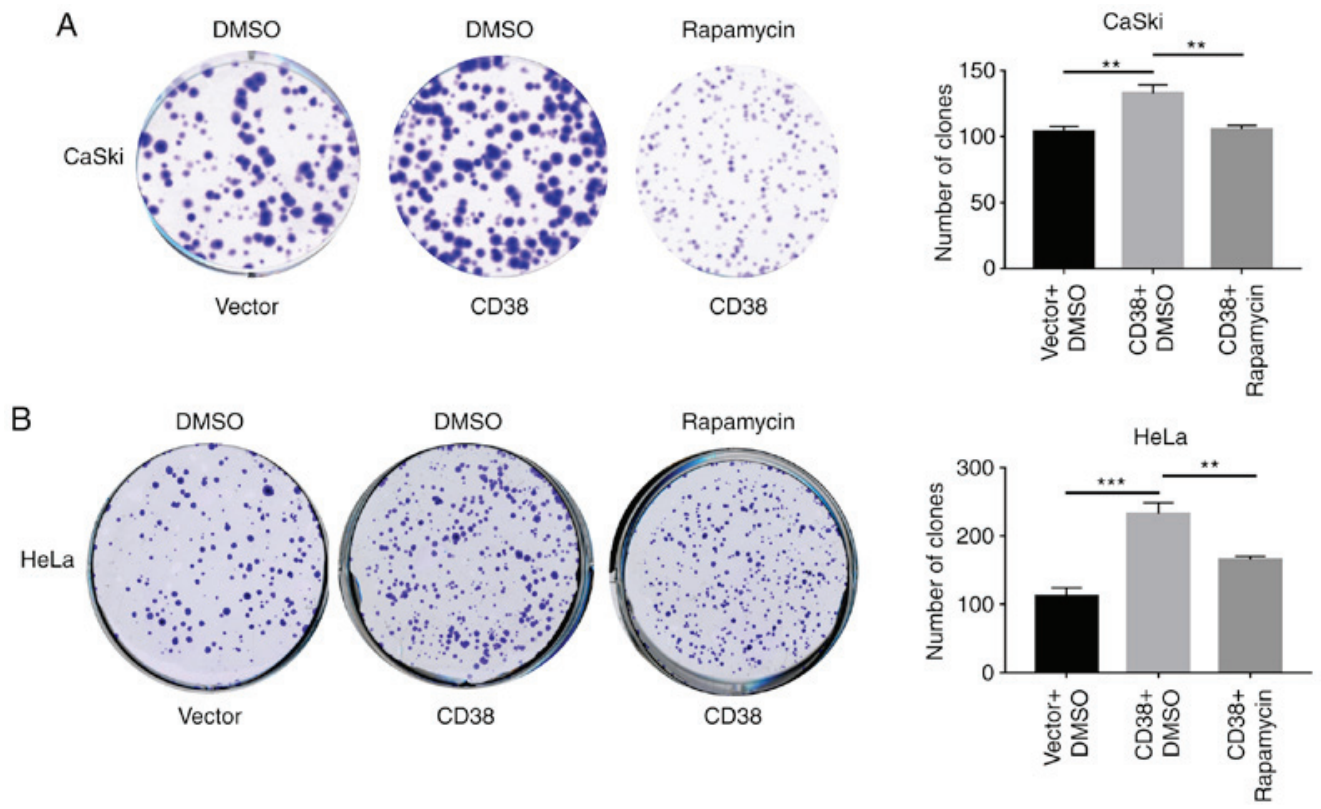

Figure 5. Effect of the mammalian target of rapamycin inhibitor, rapamycin, on the proliferation of cervical cancer cells. Colony formation assays were performed to assess the clonogenic capacity of (A) CaSki and (B) HeLa cells following CD38 overexpression and rapamycin treatment. Data are presented as the mean \pm standard deviation of three independent experiments. ${ }^{* *} \mathrm{P}<0.01,{ }^{* * *} \mathrm{P}<0.001$.

A
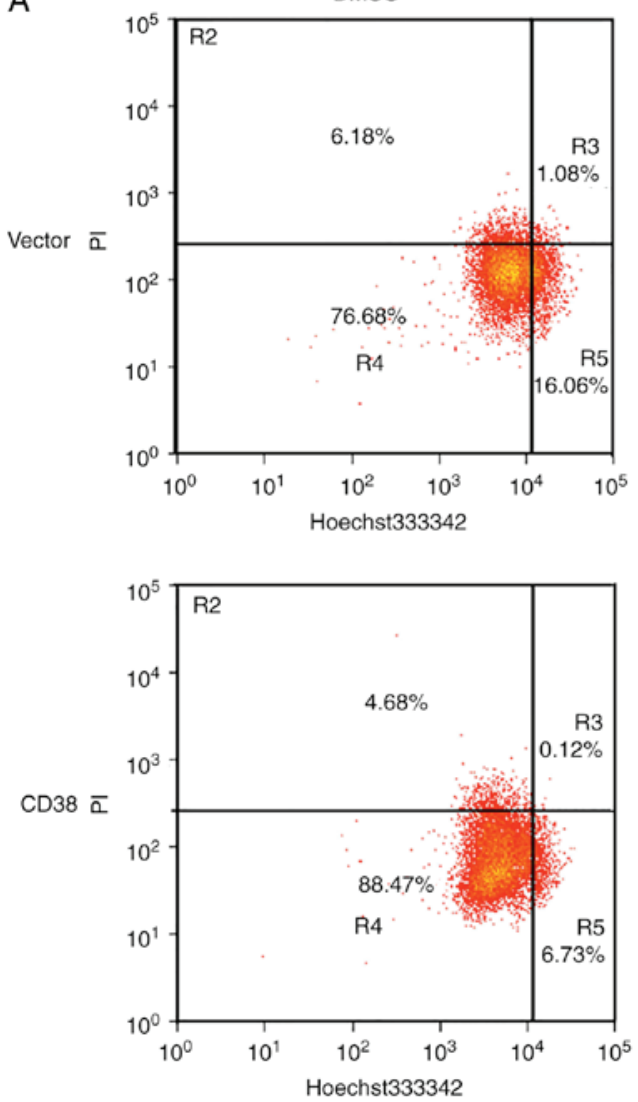
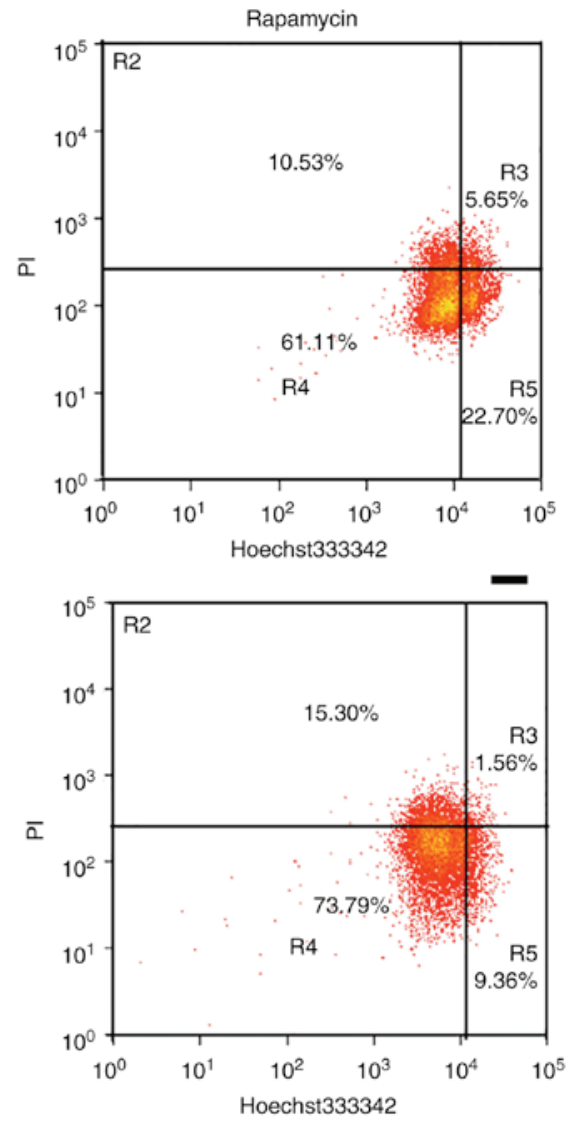

coss

Figure 6. Effect of the mammalian target of rapamycin inhibitor, rapamycin, on the apoptosis of cervical cancer cells. (A) Flow cytometry analysis of apoptosis in CaSki cells.

LDHA and ATP5H in HeLa-CD38 cells were significantly lower compared with the control HeLa-vector cells. Furthermore, the p-mTOR/mTOR ratio was significantly lower in HeLa-CD38 cells compared with HeLa-vector cells following treatment with rapamycin (Fig. 4B). These results were consistent with the results in CaSki cells. The effects of rapamycin on the ATP 
B
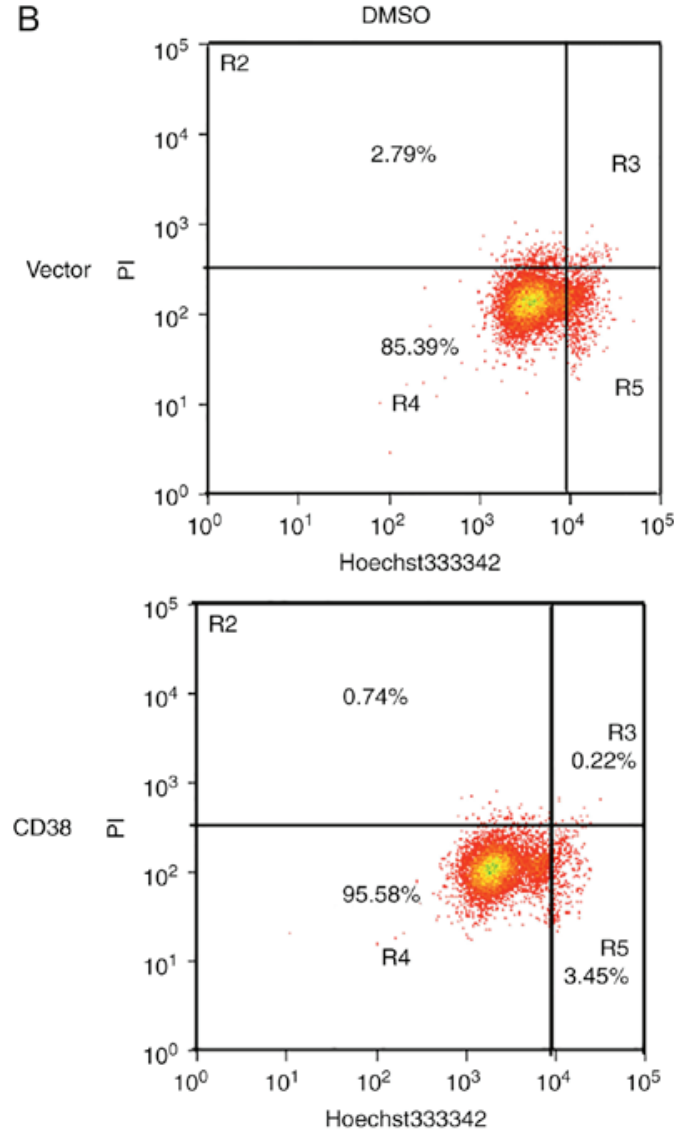
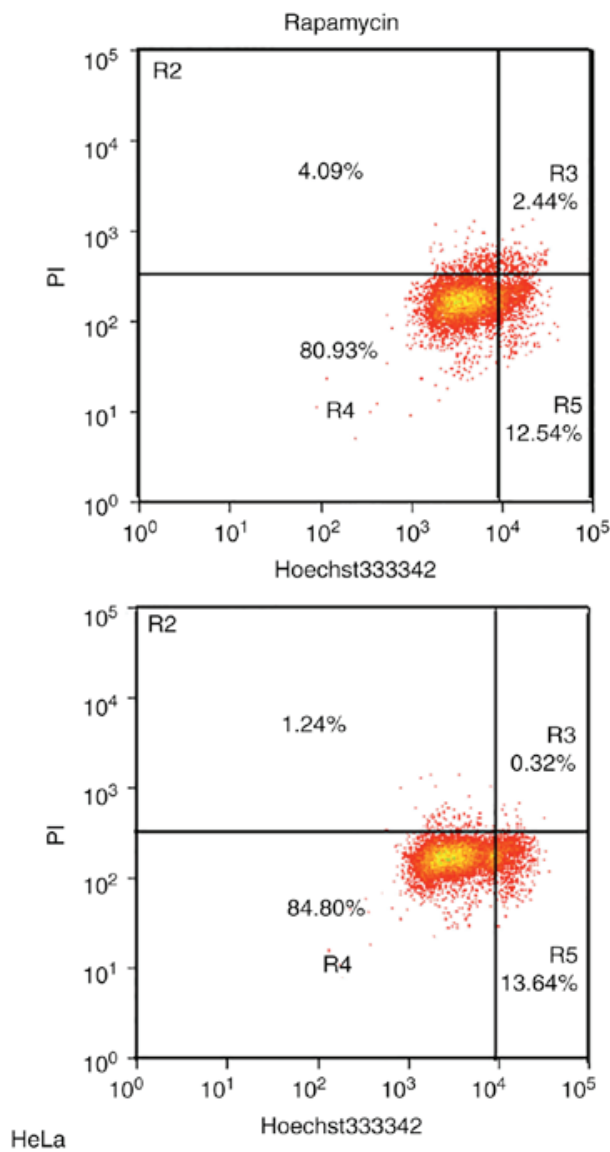

Figure 6. Continued. Effect of the mammalian target of rapamycin inhibitor, rapamycin, on the apoptosis of cervical cancer cells. (B) Flow cytometry analysis of apoptosis in HeLa cells. Cells in the R5 gate represent late apoptotic cells, and those in R3 gate are early apoptotic cells. PI, propidium iodide.

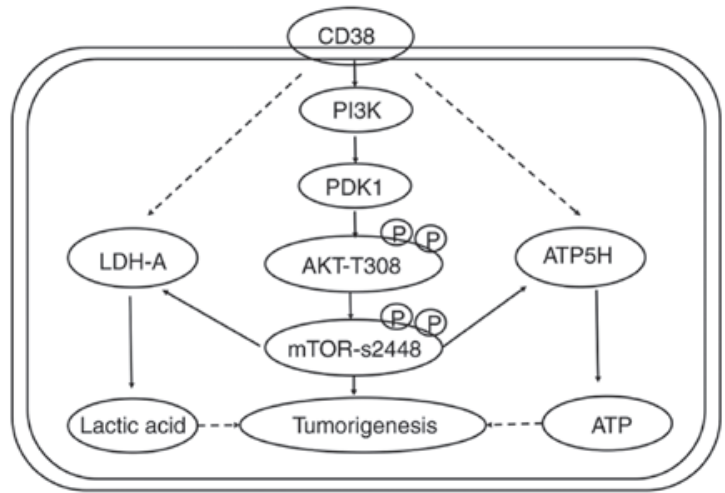

Figure 7. A diagram of CD38-mediated regulation of energy metabolism and cell proliferation of cervical cancer cells via activation of the $\mathrm{PI} 3 \mathrm{~K} / \mathrm{AKT}$ /mTOR signaling pathway. PI3K, phosphatidylinositol-4,5-bisphosphate 3-kinase; PDK1, phosphoinositide dependent protein kinase 1; AKT, Akt serine/threonine kinase; mTOR, mammalian target of rapamycin; LDH-A, lactate dehydrogenase A; ATP5H, ATP synthase peripheral stalk subunit D; p, phosphorylated.

and lactic acid levels in HeLa-CD38 cells were consistent with those observed in CaSki-CD38 cells (Fig. 4C and D). Therefore, the mTOR signaling pathway may serve a role in the effects of CD38 on the energy metabolism of cervical cancer cells. cells. The levels of lactic acid and ATP metabolites are closely associated with cell proliferation. To determine whether CD38 promotes the proliferation of cervical cancer cells by activating the PI3K/AKT/mTOR signaling pathway, cells were treated with rapamycin and the effect of $\mathrm{CD} 38$ overexpression on cell proliferation was detected using clone formation experiments. Following CD38 overexpression, the number of clones of CaSki cells treated with DMSO was significant increased, whereas following treatment with rapamycin the number of clones of CaSki-CD38 cells was significantly decreased compared with those treated with DMSO (Fig. 5A). Similar results were obtained in HeLa cells (Fig. 5B). This indicates that CD38 affects the proliferation of cervical cancer cells via the PI3K/AKT/mTOR signaling pathway.

Furthermore, apoptosis of rapamycin and DMSO-treated CaSki-CD38 and HeLa-CD38 cells was assessed. It was identified that CD38 inhibited the apoptosis of DMSO-treated cervical cancer cells $(\mathrm{P}<0.01)$, and compared with the CD38-overexpressed cells treated with DMSO, the apoptosis rate of $\mathrm{CD} 38$-overexpressed cells treated with rapamycin increased $(\mathrm{P}<0.05$; Fig. 6$)$. This indicates that the effects of CD38 on the apoptosis of cervical cancer cells may occur via the PI3K/AKT/mTOR signaling pathway (Fig. 7).

\section{Discussion}

Cellular biological processes are based on normally regulated metabolism, while metabolism in tumor cells is dysregulated, 
which leads to the abnormal survival and growth of malignant cells $(1,35)$. These changes provide sufficient energy, macromolecular precursors and reducing equivalents to support the rapid proliferation of tumor cells $(1,2)$. Cellular metabolism regulation is under precise control and the main molecules and compounds involved in regulating metabolism pathways, such as the tricarboxylic acid cycle, glycolysis, oxidative phosphorylation and the pentose phosphate pathway, have been discovered and have been subjected to intensive research (36-38). However, the exact regulatory mechanisms remain unclear.

The present study found that overexpression of CD38 was associated with changes in the levels of ATP5H-2, CYB5B, CYC1 and BRI3BP in cervical cancer cells, as well as changes in metabolic pathways, such as 'oxidative phosphorylation', 'glycosyl compound metabolic process' and 'ATP/ADP metabolic process'. Glycolysis is more active in a variety of tumors, including diffuse large B cell lymphoma $(39,40)$, uterine leiomyosarcoma (41) and lung adenocarcinoma $(42,43)$. Cancer cells often exhibit a high rate of aerobic glycolysis, which promotes cancer growth and progression by increasing glucose uptake, increasing lactic acid production and supporting energy requirements (44). Knockdown of keratin 6B significantly inhibits the expression of c-Myc, glucose uptake, lactic acid production, ATP production, extracellular acidification rate, and the protein levels of glucose transporter type 1 and lactate dehydrogenase A. Furthermore, overexpression of c-Myc reverses the decreased glycolysis and malignant phenotype in keratin 6B-knockdown cells (34). It has been proposed that oncogene expression is sufficient to reprogram certain aspects of nutrient utilization, suggesting that cell-autonomous metabolism is driven in part by oncogenes $(20,45,46)$.

$\mathrm{PI} 3 \mathrm{~K} / \mathrm{AKT} / \mathrm{mTOR}$ activation is closely associated with the occurrence, development and treatment of malignant tumors. PI3K promotes AKT and mTOR phosphorylation to activate the PI3K/AKT/mTOR signaling pathway (47). The $\mathrm{PI} 3 \mathrm{~K} / \mathrm{AKT} / \mathrm{mTOR}$ signaling pathway can mediate the downregulation of E-cadherin levels induced by insulin-like growth factor 1, ultimately leading to the proliferation of ovarian cancer cells (48). Mutations in the genes encoding members of the PI3K/AKT/mTOR pathway are often found in breast cancer (49). Mutations in this pathway are frequently associated with cell transformation, tumorigenesis, tumor progression and multidrug resistance (49).

The results of the present study demonstrated that CD38 overexpression in CaSki cells upregulated the levels of key molecules in the PI3K/AKT/mTOR signaling pathway, such as PI3K, total AKT p-AKT and p-mTOR. CD38 overexpression also upregulated p-TOR expression in HeLa cells. Treatment of cervical cancer cells stably overexpressing CD38 with rapamycin results in downregulation of $\mathrm{p}$-mTOR, and the activity of the PI3K/AKT/mTOR signaling pathway is inhibited accordingly (50). Similarly, treatment with rapamycin resulted in significantly lower levels of ATP and lactate cervical cancer cells compared with those treated with DMSO. Clonogenic assays revealed that rapamycin could reduce the proliferative phenotype of cervical cancer cells induced by CD38 overexpression. Jian et al (47) reported that interleukin-17 activates PI3K/AKT/mTOR signaling pathway and regulates lung cancer cell autophagy by downregulating the expression of Beclin 1 in lung cancer cell lines. In endometrial cancer, the $\mathrm{PI} 3 \mathrm{~K} / \mathrm{AKT} / \mathrm{mTOR}$ signaling pathway is often activated (51); however, the results of the clinical trials of PI3K/AKT/mTOR inhibitors remain controversial (52-54). New research on combination therapy using dual inhibitors, multi-channel inhibitors or other targeted drugs may result in more effective treatment (51). T cell immunoglobulin and mucin domain containing 4 can activate angiogenesis via the PI3K/AKT/mTOR signaling pathway, and then recruit tumor-related macrophages, ultimately promoting the growth of colorectal cancer (55). Cellular secretion of epidermal growth factor (EGF) plays a role in M2 polarization of macrophages in colon cancer. EGF can promote macrophage polarization to M2 via the EGF receptor/PI3K/AKT/mTOR pathway (56).

In summary, CD38 regulates glucose uptake, and intracellular ATP and lactic acid levels in cervical cancer cells by regulating the $\mathrm{PI} 3 \mathrm{~K} / \mathrm{AKT} / \mathrm{mTOR}$ signaling pathway. Ultimately, this promotes the proliferation of cervical cancer cells. Rapamycin could reverse the effect of CD38. However, to determine the exact mechanism of CD38 in the regulation of cervical cancer cell metabolism requires further experimentation.

\section{Acknowledgements}

Not applicable.

\section{Funding}

This work was supported by the National Natural Sciences Foundation of China (grant no. 81272975), the Science and Technology Foundation Survey Project of Ministry of Science and Technology of China (grant nos. 2018FY100900 and 2018FY10090004), and the Fundamental Research Funds for the Central Universities of Central South University (grant no. 2019zzts731).

\section{Availability of data and materials}

All data generated or analyzed during this study are included in this published article.

\section{Authors' contributions}

SL, CY and XJ performed the experiments. LL, JH and ZH analyzed the data. GL and YZ designed the study and wrote the manuscript. All authors read and approved the final manuscript.

\section{Ethics approval and consent to participate}

Not applicable.

\section{Patient consent for publication}

Not applicable.

\section{Competing interests}

The authors declare that they have no competing interests. 


\section{References}

1. DeBerardinis RJ, Lum JJ, Hatzivassiliou G and Thompson CB The biology of cancer: Metabolic reprogramming fuels cell growth and proliferation. Cell Metabolism 7: 11-20, 2008.

2. Vander Heiden MG, Cantley LC and Thompson CB: Understanding the Warburg effect: The metabolic requirements of cell proliferation. Science 324: 1029-1033, 2009.

3. Warburg O: On the origin of cancer cells. Science 123: 309-314, 1956.

4. Warburg O, Wind $\mathrm{F}$ and Negelein E: The metabolism of tumors in the body. J Gen Physiol 8: 519-530, 1927.

5. Lv L, Li D, Zhao D, Lin R, Chu Y, Zhang H, Zha Z, Liu Y, Li Z, $\mathrm{Xu} \mathrm{Y}$, et al: Acetylation targets the M2 isoform of pyruvate kinase for degradation through chaperone-mediated autophagy and promotes tumor growth. Mol Cell 42: 719-730, 2011.

6. Xu XD, Shao SX, Jiang HP, Cao YW, Wang YH, Yang XC, Wang YL, Wang XS and Niu HT: Warburg effect or reverse Warburg effect? A review of cancer metabolism. Oncol Res Treat 38: 117-122, 2015.

7. Liesa M and Shirihai OS: Mitochondrial dynamics in the regulation of nutrient utilization and energy expenditure. Cell Metab 17: 491-506, 2013.

8. Mitra K: Mitochondrial fission-fusion as an emerging key regulator of cell proliferation and differentiation. Bioessays 35 : 955-964, 2013

9. Youle RJ and Karbowski M: Mitochondrial fission in apoptosis Nat Rev Mol Cell Biol 6: 657-663, 2005.

10. Luo S, Li Y, Ma R, Liu J, Xu P, Zhang H, Tang K, Ma J, Liu N, Zhang Y, et al: Downregulation of PCK2 remodels tricarboxylic acid cycle in tumor-repopulating cells of melanoma Oncogene 36: 3609-3617, 2017.

11. Kerins MJ, Vashisht AA, Liang BX, Duckworth SJ, Praslicka BJ, Wohlschlegel JA and Ooi A: Fumarate mediates a chronic proliferative signal in fumarate Hydratase-inactivated cancer cells by increasing transcription and translation of ferritin genes. Mol Cell Biol 37: pii: e00079-e17, 2017.

12. Crunkhorn S: Breast cancer: Inhibiting fatty acid oxidation blocks tumour growth. Nat Rev Drug Discov 15: 310, 2016.

13. Zhu L, Ploessl K, Zhou R, Mankoff D and Kung HF: Metabolic imaging of glutamine in cancer. J Nucl Med 58: 533-537, 2017.

14. Csibi A, Fendt SM, Li C, Poulogiannis G, Choo AY, Chapski DJ, Jeong SM, Dempsey JM, Parkhitko A, Morrison T, et al: The mTORC1 pathway stimulates glutamine metabolism and cell proliferation by repressing SIRT4. Cell 153: 840-854, 2013.

15. Altman BJ, Stine ZE and Dang CV: From Krebs to clinic: Glutamine metabolism to cancer therapy. Nat Rev Cancer 16 : 619-634, 2016

16. Tedeschi PM, Bansal N, Kerrigan JE, Abali EE, Scotto KW and Bertino JR: NAD+ kinase as a therapeutic target in cancer. Clin Cancer Res 22: 5189-5195, 2016.

17. Jiang $P, D u$ W, Wang X, Mancuso A, Gao X, Wu M and Yang X: p53 regulates biosynthesis through direct inactivation of glucose-6-phosphate dehydrogenase. Nat Cell Biol 13: 310-316, 2011.

18. Dang CV: Rethinking the Warburg effect with Myc micromanaging glutamine metabolism. Cancer Res 70: 859-862, 2010.

19. Wang JB, Erickson JW, Fuji R, Ramachandran S, Gao P, Dinavahi R, Wilson KF, Ambrosio AL, Dias SM, Dang CV and Cerione RA: Targeting mitochondrial glutaminase activity inhibits oncogenic transformation. Cancer Cell 18: 207-219, 2010.

20. Gao P, Tchernyshyov I, Chang TC, Lee YS, Kita K, Ochi T, Zeller KI, De Marzo AM, Van Eyk JE, Mendell JT and Dang CV: c-Myc suppression of $\mathrm{miR}-23 \mathrm{a} / \mathrm{b}$ enhances mitochondrial glutaminase expression and glutamine metabolism. Nature 458: 762-765, 2009

21. Poulain L, Sujobert P, Zylbersztejn F, Barreau S, Stuani L, Lambert M, Palama TL, Chesnais V, Birsen R, Vergez F, et al: High mTORC1 activity drives glycolysis addiction and sensitivity to G6PD inhibition in acute myeloid leukemia cells. Leukemia 31: 2326-2335, 2017.

22. Oronsky BT, Oronsky N, Fanger GR, Parker CW, Caroen SZ, Lybeck M and Scicinski JJ: Follow the ATP: Tumor energy production: A perspective. Anticancer Agents Med Chem 14 1187-1198, 2014.

23. Rah SY and Kim UH: CD38-mediated $\mathrm{Ca}^{2+}$ signaling contributes to glucagon-induced hepatic gluconeogenesis. Sci Rep 5: 10741, 2015 .
24. Mehta K, Shahid U and Malavasi F: Human CD38, a cell-surface protein with multiple functions. FASEB J 10: 1408-1417, 1996.

25. Malavasi F, Funaro A, Roggero S, Horenstein A, Calosso L and Mehta K: Human CD38: A glycoprotein in search of a function. Immunol Today 15: 95-97, 1994.

26. Chini EN: CD38 as a regulator of cellular NAD: A novel potential pharmacological target for metabolic conditions. Curr Pharm Des 15: 57-63,2009.

27. Zocchi E, Daga A, Usai C, Franco L, Guida L, Bruzzone S, Costa A, Marchetti C and De Flora A: Expression of CD38 increases intracellular calcium concentration and reduces doubling time in HeLa and 3 T3 cells. J Biol Chem 273: 8017-8024, 1998

28. Long AN, Owens K, Schlappal AE, Kristian T, Fishman PS and Schuh RA: Effect of nicotinamide mononucleotide on brain mitochondrial respiratory deficits in an Alzheimer's disease-relevant murine model. BMC Neurol 15: 19, 2015.

29. Hayakawa K, Esposito E, Wang X, Terasaki Y, Liu Y, Xing C, Ji X and Lo EH: Transfer of mitochondria from astrocytes to neurons after stroke. Nature 535: 551-555, 2016.

30. Liao S, Xiao S, Chen H, Zhang M, Chen Z, Long Y, Gao L, Zhu G, He J, Peng S, et al: CD38 enhances the proliferation and inhibits the apoptosis of cervical cancer cells by affecting the mitochondria functions. Mol Carcinog 56: 2245-2257, 2017.

31. Liao S, Xiao S, Zhu G, Zheng D, He J, Pei Z, Li G and Zhou Y: CD38 is highly expressed and affects the PI3K/Akt signaling pathway in cervical cancer. Oncol Rep 32: 2703-2709, 2014.

32. Zhu GC, Gao L, He J, Long Y, Liao S, Wang H, Li X, Yi W, Pei Z, $\mathrm{Wu} \mathrm{M}$, et al: CD90 is upregulated in gastric cancer tissues and inhibits gastric cancer cell apoptosis by modulating the expression level of SPARC protein. Oncol Rep 34: 2497-2506, 2015.

33. Li H, Li X, Ge X, Jia L, Zhang Z, Fang R, Yang J, Liu J, Peng S, Zhou M, et al: MiR-34b-3 and miR-449a inhibit malignant progression of nasopharyngeal carcinoma by targeting lactate dehydrogenase A. Oncotarget 7: 54838-54851, 2016.

34. Luo P, Zhang C, Liao F, Chen L, Liu Z, Long L, Jiang Z, Wang Y, Wang Z, Liu Z, et al: Transcriptional positive cofactor 4 promotes breast cancer proliferation and metastasis through c-Myc mediated Warburg effect. Cell Commun Signal 17: 36, 2019.

35. Hensley CT, Faubert B, Yuan Q, Lev-Cohain N, Jin E, Kim J, Jiang L, Ko B, Skelton R, Loudat L, et al: Metabolic heterogeneity in human lung tumors. Cell 164: 681-694, 2016.

36. Kletzien RF, Harris PK and Foellmi LA: Glucose-6-phosphate dehydrogenase: A 'housekeeping' enzyme subject to tissue-specific regulation by hormones, nutrients, and oxidant stress. FASEB J 8: 174-181, 1994.

37. Stanton RC: Glucose-6-phosphate dehydrogenase, NADPH, and cell survival. IUBMB Life 64: 362-369, 2012.

38. Wood T: Physiological functions of the pentose phosphate pathway. Cell Biochem Funct 4: 241-247, 1986.

39. Compagno M, Lim WK, Grunn A, Nandula SV, Brahmachary M, Shen Q, Bertoni F, Ponzoni M, Scandurra M, Califano A, et al: Mutations of multiple genes cause deregulation of NF-kappaB in diffuse large B-cell lymphoma. Nature 459: 717-721, 2009.

40. Rosenwald A, Wright G, Chan WC, Connors JM, Campo E, Fisher RI, Gascoyne RD, Muller-Hermelink HK, Smeland EB, Giltnane JM, et al: The use of molecular profiling to predict survival after chemotherapy for diffuse large-B-cell lymphoma. N Engl J Med 346: 1937-1947, 2002.

41. Quade BJ, Wang TY, Sornberger K, Dal Cin P, Mutter GL and Morton CC: Molecular pathogenesis of uterine smooth muscle tumors from transcriptional profiling. Genes Chromosomes Cancer 40: 97-108, 2004

42. Stearman RS, Dwyer-Nield L, Zerbe L, Blaine SA, Chan Z, Bunn PA Jr, Johnson GL, Hirsch FR, Merrick DT, Franklin WA, et al: Analysis of orthologous gene expression between human pulmonary adenocarcinoma and a carcinogen-induced murine model. Am J Pathol 167: 1763-1775, 2005.

43. Su LJ, Chang CW, Wu YC, Chen KC, Lin CJ, Liang SC, Lin CH, Whang-Peng J, Hsu SL, Chen CH and Huang CY: Selection of DDX 5 as a novel internal control for Q-RT-PCR from microarray data using a block bootstrap re-sampling scheme. BMC Genomics 8: 140, 2007.

44. Gatenby RA and Gillies RJ: Why do cancers have high aerobic glycolysis? Nat Rev Cancer 4: 891-899, 2004.

45. Ji H, Ramsey MR, Hayes DN, Fan C, McNamara K, Kozlowski P, Torrice C, Wu MC, Shimamura T, Perera SA, et al: LKB1 modulates lung cancer differentiation and metastasis. Nature 448: 807-810, 2007. 
46. Son J, Lyssiotis CA, Ying H, Wang X, Hua S, Ligorio M, Perera RM, Ferrone CR, Mullarky E, Shyh-Chang N, et al: Glutamine supports pancreatic cancer growth through a KRAS-regulated metabolic pathway. Nature 496: 101-105, 2013.

47. Jian M, Yunjia Z, Zhiying D, Yanduo J and Guocheng J: Interleukin 7 receptor activates PI3K/Akt/mTOR signaling pathway via downregulation of Beclin-1 in lung cancer. Mol Carcinog 58: 358-365, 2019.

48. Lau MT and Leung PC: The PI3K/Akt/mTOR signaling pathway mediates insulin-like growth factor 1-induced E-cadherin down-regulation and cell proliferation in ovarian cancer cells. Cancer Lett 326: 191-198, 2012.

49. Guerrero-Zotano A, Mayer IA and Arteaga CL: PI3K/AKT/mTOR: Role in breast cancer progression, drug resistance, and treatment. Cancer Metastasis Rev 35: 515-524, 2016.

50. Takeuchi H, Kondo Y, Fujiwara K, Kanzawa T, Aoki H, Mills GB and Kondo S: Synergistic augmentation of rapamycin-induced autophagy in malignant glioma cells by phosphatidylinosito 3-kinase/protein kinase B inhibitors. Cancer Res 65: 3336-3346, 2005.

51. Barra F, Evangelisti G, Ferro Desideri L, Di Domenico S, Ferraioli D, Vellone VG, De Cian F and Ferrero S: Investigational $\mathrm{PI} 3 \mathrm{~K} / \mathrm{AKT} / \mathrm{mTOR}$ inhibitors in development for endometrial cancer. Expert Opin Investig Drugs 28: 131-142, 2019.
52. Fleming GF, Filiaci VL, Marzullo B, Zaino RJ, Davidson SA, Pearl M, Makker V, Burke JJ II, Zweizig SL, Van Le L, et al: Temsirolimus with or without megestrol acetate and tamoxifen for endometrial cancer: A gynecologic oncology group study. Gynecol Oncol 132: 585-592, 2014.

53. Colombo N, McMeekin S, Schwartz P, Kostka J, Sessa C, Holloway PG, Braly P, Matei D and Einstein M: A phase II trial of the mTOR inhibitor AP23573 as a single agent in advanced endometrial cancer. J Clin Oncol 25 (18 Suppl): S5516, 2007.

54. Tsoref D, Welch S, Lau S, Biagi J, Tonkin K, Martin LA, Ellard S, Ghatage P, Elit L, Mackay HJ, et al: Phase II study of oral ridaforolimus in women with recurrent or metastatic endometrial cancer. Gynecol Oncol 135: 184-189, 2014.

55. Tan X, Zhang Z, Yao H and Shen L: Tim-4 promotes the growth of colorectal cancer by activating angiogenesis and recruiting tumor-associated macrophages via the PI3K/AKT/mTOR signaling pathway. Cancer Lett 436: 119-128, 2018.

56. Lian G, Chen S, Ouyang M, Li F, Chen L and Yang J: Colon cancer cell secretes EGF to promote M2 polarization of TAM through EGFR/PI3K/AKT/mTOR pathway. Technol Cancer Res Treat 18: 1533033819849068, 2019. 